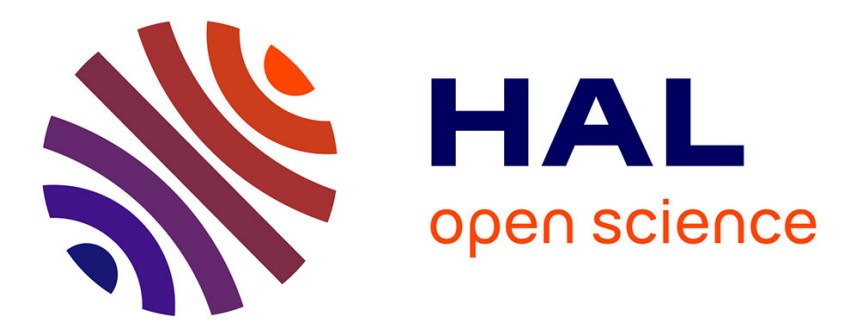

\title{
Production and Patterning of Liquid Phase-Exfoliated 2D Sheets for Applications in Optoelectronics
} Samanta Witomska, Tim Leydecker, Artur Ciesielski, Paolo Samorì

\section{To cite this version:}

Samanta Witomska, Tim Leydecker, Artur Ciesielski, Paolo Samorì. Production and Patterning of Liquid Phase-Exfoliated 2D Sheets for Applications in Optoelectronics. Advanced Functional Materials, In press, pp.1901126. 10.1002/adfm.201901126 . hal-02072144

\section{HAL Id: hal-02072144 \\ https://hal.science/hal-02072144}

Submitted on 18 Mar 2019

HAL is a multi-disciplinary open access archive for the deposit and dissemination of scientific research documents, whether they are published or not. The documents may come from teaching and research institutions in France or abroad, or from public or private research centers.
L'archive ouverte pluridisciplinaire HAL, est destinée au dépôt et à la diffusion de documents scientifiques de niveau recherche, publiés ou non, émanant des établissements d'enseignement et de recherche français ou étrangers, des laboratoires publics ou privés. 


\section{WILEY-VCH}

DOI: 10.1002/ ((please add manuscript number))

Article type: ((Review))

Production and patterning of liquid-phase exfoliated 2D sheets for applications in optoelectronics

Samanta Witomska, Tim Leydecker, Artur Ciesielski, * Paolo Samori*

S. Witomska, Dr. T. Leydecker, Dr. A. Ciesielski, Prof. P. Samorì

Université de Strasbourg, CNRS, ISIS,

8 alleé Gaspard Monge, 67000 Strasbourg, France

E-mail: ciesielski@unistra.fr, samori@unistra.fr

S. Witomska, Dr. A. Ciesielski,

Center for Advanced Technologies, Adam Mickiewicz University

Umultowska 89c, 61614 Poznań, Poland

S. Witomska,

Faculty of Chemistry, Adam Mickiewicz University

Umultowska 89b, 61614 Poznań, Poland

Keywords: liquid-phase exfoliation, 2D materials, graphene, conductive thin-films 


\section{WILEY-VCH}

\section{Abstract}

Two-dimensional (2D) materials (2DMs), which can be produced by exfoliating bulk crystals of layered materials, display unique optical and electrical properties making them attractive components for a wide range of technological applications. In this context, attaining a full control over the generation of high-quality $2 \mathrm{DMs}$ with methods that can be employed for large-scale production of exfoliated nanosheets and inks thereof represents a major challenge of potential technological interest in the numerous fields, even beyond opto-electronics and sensing, such as those associated to energy applications. This Review describes the most recent developments in the production of high-quality 2DMs based inks using liquid-phase exfoliation (LPE), combined with the patterning approaches, highlighting convenient and effective methods for generating materials and films with controlled thicknesses down to the atomic scale. Different processing strategies which can be employed to deposit the produced inks as patterns and functional thin-films are introduced, by focussing on those that can be easily translated to the industrial scale such as coating, spraying and various printing technologies. By providing insight into the multiscale analyses of numerous physical and chemical properties of these functional films and patterns, with a specific focus on their extraordinary electronic characteristics, this Review offers the readers crucial information for a profound understanding of the fundamental properties of these patterned surfaces as the millstone towards the generation of novel multifunctional devices. Finally, we discuss the challenges and opportunities associated to the 2DMs' integration into working opto-electronic (nano)devices. 


\section{WILEY-VCH}

\section{Introduction}

The cutting-edge results by Geim and Novoselov on the extraordinary physical properties possessed by graphene, has seeded and catalysed a tremendous effort on the development of new protocols to controllably exfoliate single layers (SLs) of other two-dimensional (2D) materials starting from their multi-layered bulk analogues. In parallel, such unique properties have also triggered immense research endeavours on the use of such materials for applications in numerous technological fields. In particular, 2D transition metal dichalcogenides (TMDs), such as SL of molybdenum (IV) disulfide $\left(\mathrm{MoS}_{2}\right)$, molybdenum (IV) diselenide $\left(\mathrm{MoSe}_{2}\right)$, tungsten (IV) disulfide $\left(\mathrm{WS}_{2}\right)$, tungsten (IV) diselenide $\left(\mathrm{WSe}_{2}\right)$, etc., black phosphorus (BP) or hexagonal boron nitride (h-BN) and have emerged in the last years as complementary materials to graphene and are being extensively explored as potential components in the nextgeneration flexible (opto-)electronic devices.

Graphene is an attractive 2D nanomaterial which has revolutionized the field of nanoscience and nanotechnology due its high thermal conductivity $\left(5000 \mathrm{~W} \mathrm{~m}^{-1} \mathrm{~K}^{-1}\right)^{[1]}$ and high optical transmittance reaching 98\%, ${ }^{[2]}$ large (theoretical) specific surface area $\left(2630 \mathrm{~m}^{2} \mathrm{~g}^{-1}\right)^{[3]}$ and outstanding mechanical strength and flexibility (Young's modulus $\sim 1 \mathrm{TPa}$ ). ${ }^{[4]}$ Alongside graphene, other 2D materials are attracting more and more interest because of their exceptional chemical and physical properties along with their thermal stabilities. Among them, group-6 semiconducting TMDs, in their SL form, display a sizeable direct energy bandgap (1-3 eV), extremely high $\mathrm{I}_{\mathrm{on}} / \mathrm{I}_{\text {off }}$ ratios reaching $\sim 10^{8}$ and field-effect mobilities within the $10-100 \mathrm{~cm}^{2} \mathrm{~V}^{-1} \mathrm{~s}^{-1}$ range. ${ }^{[5]}$ Conversely, h-BN was found to be an electrical insulator (band gap of $\sim 6 \mathrm{eV}$ ). ${ }^{[6]}$ Additional, metal halides (such as $\mathrm{PbI}_{2}$ and $\mathrm{MgBr}_{2}$ ), layered metal oxide (such as $\mathrm{MnO}_{2}, \mathrm{MoO}_{3}$ and $\mathrm{LaNb}_{2} \mathrm{O}_{7}$ ), black phosphorus (BP) and also silicates represent interesting alternative layered compounds exhibiting distinctive properties. Such diversity of properties renders 2D materials (2DMs) ideal components for a variety of 


\section{WILEY-VCH}

technological applications, which include thin film transistors, transparent and flexible electronics, memory devices, light-emitting diodes, solar cells, sensors, etc.

Since the physical and chemical properties of 2DMs are unique and strongly dependent on their thickness at the very atomic-scale, ${ }^{[7]}$ establishing exfoliation or delamination processes to produce extremely thin sheets from layered system is of paramount importance. The deposition of such sheets to generate films is also crucial towards their use as electrodes or active components in many applications in opto-electronics, energy storage and generation as well as functional composites/foams for sensing, mechanical reinforcement and gas/ion barriers. ${ }^{[8]}$ Depending on the employed exfoliation method, the obtained materials can be extremely defective or almost defect-free, which are critical factors for their integration in working devices. Hitherto, different methods have been employed to produce 2DMs, and each of them yields material with drastically different properties.

This Review briefly introduces the recent advancements in the generation of atomically thin 2D nanosheets by means of an extremely mild and easily up-scalable top-down approach, i.e. the liquid-phase exfoliation. We discuss the wide range of techniques that can be used towards the deposition of the produced inks into space confined patterns or continuous thinfilms. We examine aspects related to the structure $v s$. property relationship. In particular, we focus on the importance of reaching a fine control over the material's properties through a detailed understanding over their structure on the nanometer- to sub-nanometer-scale and interconnectivity between deposited sheets. Achieving such a thorough control will make it possible to harness the electrical and optical properties of the 2D nanosheets, being a mandatory step towards the realization of commercial high-performance applications based on 2DMs.

\section{Production techniques}




\section{WILEY-VCH}

2DMs can be produced by using either bottom-up or top-down production strategies. ${ }^{[9]}$ The use of bottom-up techniques, such as chemical vapour deposition (CVD) ${ }^{[9-10]}$ and epitaxial growth, ${ }^{[9,11]}$ makes it possible to generate high quality materials with small number of defects, which makes them good candidates for applications in nanoelectronics. However, these substrate-based techniques suffer from the limited scale and expensive production. Conversely, the production of 2D materials by means of low-cost and up-scalable methods has been demonstrated by employing top-down techniques, which are based on the mechanical cleavage of layered materials using exfoliation methods.

Numerous 2DMs exist in their bulk form as stacks of multi-layered architectures. They all share a common structural characteristic, i.e. their composing atoms are held together in-plane by strong covalent forces whereas their inter-plane interactions are much weaker, usually being of van der Waals type. Upon breaking these weak bonds two-dimensional nanomaterials can be exfoliated into individual flakes or few-layered (FL) sheets. Among various exfoliation techniques, liquid-phase exfoliation (LPE) is extremely appealing since it allows the production of highly-concentrated inks of 2DMs, which can be deposited on different substrates by means of printing or other methods, enabling large-area patterning. LPE process typically involves three steps: dispersion of layered material in a liquid media, exfoliation and purification, which is necessary to separate exfoliated from un-exfoliated flakes is usually carried out via ultracentrifugation. ${ }^{[7,12]}$ The successful exfoliation occurs by overcoming the van der Waals (dispersive London type) interactions holding together adjacent layers. Immersion in a liquid represents one of the most effective method to reduce the strength of these attractive forces. ${ }^{[13]}$ When a solid surface is immersed in a liquid medium the interfacial tension is high, therefore the dispersibility of the solid in the liquid is poor. The suitable solvent balances the inter-sheet attractive forces and stabilizes the nanosheets against 


\section{WILEY-VCH}

aggregation. The solvents which turned out being suitable to disperse $2 \mathrm{D}$ sheets are those that minimize the interfacial tension $\left[\mathrm{mN} \mathrm{m}^{-1}\right]$ between the liquid and the $2 \mathrm{D}$ flakes. ${ }^{[12]}$

Given that the properties of 2D sheets strongly depend on their lateral and vertical sizes, it is important to note that liquid-dispersed sheets can be sorted by thickness and size, which is instrumental for the production of high-quality functional films. ${ }^{[10 b]}$ Interestingly, such an approach is applicable to a widest range of layered materials. ${ }^{[14]}$ This Review introduces the reader to the various LPE based methods such as ultrasound induced LPE (UILPE), ${ }^{[15]}$ electrochemical exfoliation (EE), ${ }^{[16]}$ high-shear mixing exfoliation (HSE), ${ }^{[17]}$ solvothermalassisted LPE (SALPE), ${ }^{[18]}$ microfluidization ${ }^{[19]}$ and ball-milling ${ }^{[20]}$ (see Figure 1). The LPE strategy is gaining attention because it represents a potentially up-scalable route for the massproduction of inks of a wide variety of 2D nanomaterials, yet not all LPE approaches can meet the requirements of industrial protocols. Significantly, it is extremely versatile, costeffective and does not require specific substrate and production conditions (high vacuum and temperature) towards the 2DM integration in working devices.

The LPE approach can be assisted by the simultaneous chemical treatments of 2DMs with e.g. $n$-butyllithium or inorganic acids to obtain colloidal stable suspensions. ${ }^{[21]}$ Such a combined approach render it possible to exfoliate other interesting classes of 2DMs such as graphene oxide (GO) or 2D carbides and nitrides (MXenes). ${ }^{[22]}$ However, the use of such chemical treatment is beyond the focus of this Review article, therefore it is not included below.

\subsection{Characterization method}

Both qualitative and quantitative information are required in order to thoroughly characterize the materials exfoliated via LPE methods. In particular, spectroscopic and microscopic characterizations of exfoliated 2DMs are vital to determine exfoliation yields and full understanding of the overall 2DMs' properties as well as the morphology of the exfoliated 


\section{WILEY-VCH}

flakes (size, shape and thickness). Nowadays, there are a vast number of characterization techniques that can be utilized to investigate 2DMs' properties in a fast and non-destructive manner. Noteworthy, most of these techniques can be used in laboratories and at massproduction sites. The lateral size, morphology, shape and thickness of the $2 \mathrm{D}$ nanosheets are usually determined via microscopic characterization by high-resolution transmission electron microscopy (HR-TEM) and atomic force microscopy (AFM) (see examples in Fig. 2). While the former allows the estimation of the number of layers of exfoliated $\left(\mathrm{N}_{\mathrm{L}}\right)$ sheets by counting the number of sheet's edges and by using electron diffraction patterns, ${ }^{[23]}$ the latter enables the estimation of $\mathrm{N}_{\mathrm{L}}$ by measuring the height of the flakes and dividing it by the corresponding interlayer distance. ${ }^{[24]}$ Yet, it is important to note that estimation of SL flakes height via AFM varies with the nature of the substrate (e.g. roughness, hydrophobicity or hydrophilicity) and depends on the magnitude of the force applied by the tip to the sample as well as the experimental conditions such as relative humidity. ${ }^{[25]}$ Nevertheless, AFM can be employed to gain in-depth insight into the surface morphology of exfoliated flakes of 2DMs, as shown in Fig. $2 \mathrm{a}$ and $2 \mathrm{~d}$ for graphene and $h$-BN, respectively. Moreover, AFM can reveal the presence of structural defects on the surface of SL graphene flake (Fig. 2b). ${ }^{[25]}$

Recently, Backes et al. ${ }^{[29]}$ introduced photoluminescence excitation spectroscopy as a mean to identify the $\mathrm{N}_{\mathrm{L}}$ in $\mathrm{MoS}_{2}$ and other TMDs ${ }^{[30]}$ as well as BP. ${ }^{[31]}$ Another widely utilized spectroscopic technique is Raman spectroscopy, ${ }^{[32]}$ which is commonly used to examine whether the exfoliated material is structurally similar to the bulk material and more importantly how much defects (if any) are introduced during LPE process. Raman spectroscopy is also a powerful tool to identify unwanted by-products, structural damage and doping of 2DMs. It has been a key experimental technique to study the bonding nature of graphene ${ }^{[33]}$ or $\mathrm{MoS}_{2} \cdot{ }^{[34]}$ The main features in the Raman spectra of graphitic carbon-based materials are the $\mathrm{G}\left(1580 \mathrm{~cm}^{-1}\right)$ and $\mathrm{D}\left(1350 \mathrm{~cm}^{-1}\right)$ peaks and their overtones. ${ }^{[35]}$ The overtone 


\section{WILEY-VCH}

of the D peak, called 2D peak, appears around $2680 \mathrm{~cm}^{-1}$, and its shift and shape has been correlated with the number of graphene layers (Fig. 3). ${ }^{[23 a, 36]}$ Furthermore, the intensity ratio $\mathrm{I}_{\mathrm{D}} / \mathrm{I}_{\mathrm{G}}$ is commonly used to quantify the disorder level in graphene. ${ }^{[37]}$ After a certain degree of disorder the addition of defects lead to an attenuation of the peaks, and consequently, to a decrease of the $\mathrm{I}_{\mathrm{D}} / \mathrm{I}_{\mathrm{G}}$ ratio. Raman spectroscopy shows also its potential for different types of 2D layered materials. ${ }^{[38]}$ The anomalous frequency trends for $\mathrm{E}^{1}{ }_{2 \mathrm{~g}}$ and $\mathrm{A}_{\mathrm{g}}{ }_{\mathrm{g}}$ modes for $\mathrm{MoS}_{2}$ and $\mathrm{WS}_{2}$ can be used for layer thickness determination for 1-5 layers $\mathrm{MoS}_{2} / \mathrm{WS}_{2}$ (Fig. 3). ${ }^{[38 \mathrm{a} \text {, }}$ ${ }^{38 c]}$ Nevertheless, it is not enough for 2D flakes with layer number greater than 5 . Besides the information on layer thickness of TMDs, ${ }^{[38 c]}$ Raman spectroscopy can provide details about atomic coordination and crystal lattice, e.g. trigonal prismatic $(2 \mathrm{H}) v$ s. octahedral $(1 \mathrm{~T}) .{ }^{[39]}$ Figure $3 \mathrm{c}$ presents also the Raman spectra of BP as a function of the number of atomic layers, from the SL to an optically thick bulk sample. ${ }^{[40]}$ From bulk to atomically thin samples, slight frequency variations and the appearance of two new Raman active vibrational modes located above $\mathrm{A}_{\mathrm{g}}{ }_{\mathrm{g}}$ and $\mathrm{A}_{\mathrm{g}}^{2}$, were observed. It is important to note, that the Raman spectrum of 2DM' sheets produced by LPE differs from the one of 2DMs produced by micromechanical exfoliation (MME) using the scotch tape approach. ${ }^{[41]}$ This can be anticipated since during LPE process, the material is strongly interacting with the solvent and as in the case of UILPE it is subjected to strong mechanical stress because of the collapse of bubbles and voids in the liquid, which results in the fragmentation of the flakes: overall the LPE may produce significant changes in the Raman peaks, which could be related to structural changes, but also doping - caused by solvent residuals, and re-stacking of the exfoliated sheets.

X-ray photoelectron spectroscopy (XPS) represents a powerful tool to analyse the chemical components and electronic states of the elements in the graphene and other 2DMs. Moreover, XPS analysis allows monitoring of chemical composition of the material as a function of LPE duration. Changes on the XPS spectrum of exfoliated graphene can be follow on the C1s 


\section{WILEY-VCH}

spectrum, as shown in Figure 4a. ${ }^{[25]}$ Oxidation of the material during LPE is observed on the C1s spectrum of graphene, compare to pristine graphite (Fig. 4a). Moreover, the content of oxygen, and consequently the $\mathrm{C} / \mathrm{O}$ ratio determined by XPS can be used for comparing samples of different research groups. XPS spectroscopy can also be employed to evaluate the composition of $1 \mathrm{~T}$ and $2 \mathrm{H}$ phases for the TMDs like $\mathrm{MoS}_{2}$ (Fig. 4b-c). ${ }^{[16 b, 42]}$ Kang et al. ${ }^{[43]}$ presented spectroscopic analysis of BP nanosheets using XPS, as shown in Fig. 4. Small oxidized phosphorus (i.e., $\mathrm{PO}_{\mathrm{x}}$ ) bands are also apparent on the XPS spectra (Fig. 4d). Oxygen defect are introduced during solvent exfoliation. Additionally, Figure 4d reveals that, despite 1, 2, 3, and 7 days of ambient exposure the $\mathrm{BP}$ nanosheets, the $\mathrm{PO}_{\mathrm{x}}$ content are similar, indicating slowed ambient degradation of BP nanosheets obtained by LPE, compare to mechanical exfoliation. ${ }^{[44]}$

The current state-of-the-art on the successful LPE procedures by providing a quantitative description and mechanism of the most relevant production procedures exploited to exfoliate high-quality 2D materials are detailed below.

\subsection{Ultrasound induced liquid phase exfoliation (UILPE)}

Ultrasounds induced liquid-phase exfoliation (UILPE) process is one among the most straightforward approaches for the production of homogeneous dispersions of 2DMs, being commonly exploited to exfoliate layers from bulk materials in liquid media. Noteworthy, the quality of 2D nanosheets produced by UILPE method is affected by the exfoliation medium (water or organic solvents), the experimental set-up (probe or bath sonication) and by the parameters (conditions) used for the exfoliation. The role played by the exfoliation medium, such as (organic) solvents, stabilizing agents as surfactant/water solutions, ionic liquid, salts and polymer solution etc., has been discussed in several up-to-date reviews. ${ }^{[12,15 b, 45]}$ During ultrasonication, shear forces and cavitation, that are consequence of the growth and collapse 


\section{WILEY-VCH}

of the micrometer-sized bubbles or voids in liquids due to pressure fluctuations, act on the bulk material breaking up the layered structure and induce exfoliation to produce SL or FL nanosheets. ${ }^{[13]}$

It is commonly accepted that the liquids with a surface tension of around $40 \mathrm{~mJ} \mathrm{~m}^{-2}$ are applicable for the dispersing of graphene, graphitic flakes and TMDs. ${ }^{[46]}$ However, majority of nanosheets are obtained at room-temperature and short sonication time, and therefore it is important to note that if the temperature is increased, the surface tension will vary. A library of organic solvents was exploited in the pioneering work of Coleman's group in $2008,{ }^{[23 b]}$ and only a few solvents have been selected and are being used worldwide as optimal UILPE media. These include N,N-dimethylformamide (DMF) and N-methyl-2- pyrrolidone (NMP) ortho-dichlorobenzene (o-DCB). In particular, dispersion of SL and FL graphene nanosheets have been obtained in NMP at concentrations of up to $0.01 \mathrm{mg} \mathrm{mL}^{-1}$. However, such a concentration is far too low to meet the industrial demands and find practical application. Undoubtedly, the selection of ultrasonication parameters such as time and power plays an important role during the UILPE and there are extensively investigated to increase the yield of the exfoliation process. In the past, we examined the effect of the ultrasonication power in both NMP or $o$-DCB. ${ }^{[15 a]}$ Towards this end, we have carried out the UILPE at $600 \mathrm{~W}$ and $1000 \mathrm{~W}$. The analysis of independent UILPE experiments revealed that when UILPE is performed at $600 \mathrm{~W}$, comparable values of exfoliation yields, and in particular the concentration of obtained dispersions in NMP and o-DCB are obtained. It was concluded that the exfoliation yield of NMP-based dispersions does not depend on the power of the ultrasonic bath, while the concentration of dispersions obtained from $o$-DCB decreased drastically. These results highlight the importance of the choice of the UILPE solvents. Moreover, the power of ultrasonication can strongly influence on the lateral size of the exfoliated SL and FL nanosheets in $o$-DCB. In particular, when UILPE is carried out at 600 


\section{WILEY-VCH}

$\mathrm{W}$, the dispersions have been found to be composed of graphene nanosheets with a lateral size of $180 \mathrm{~nm}$, whereas at higher power $(1000 \mathrm{~W})$ graphene nanodots (GNDs) with an average width of $\sim 17 \mathrm{~nm}$ have been produced. While in the specific case the great difference in the lateral size of the exfoliated sheets can be ascribed to the sonication-induced activation of chemical processes such as radical formation in the $o$-DCB solvent molecules, which are highly reactive species that can strongly interact with the graphene flakes during the exfoliation thereby determining their lateral size, other physical phenomena can be brought into play by varying the sonication power.

Numerous attempts have been made to increase the yields of the UILPE by exploring parameters such as severely longer sonication (up to ca. $500 \mathrm{hrs}$ ). ${ }^{[47]}$ Nevertheless, such timeconsuming method demands high energy input and results in the severely reduced size of the flakes. ${ }^{[48]}$ In addition to the reduced size of the produced flakes, long sonication of graphite can also affect the quality of the produced graphene. For short ultrasound treatments the exfoliated graphene displays defects predominantly at the edges of the graphene flakes whereas the basal plane of the flakes is defect free. ${ }^{[48]}$ Yet, the prolonged sonication significantly affects the morphology of the flakes. In particular, defect formation during cavitation was precisely monitored by Bracamone et al. ${ }^{[49]}$ It was found that for short sonication (30 min) defects are located mainly at the edges of the flakes, while they start appearing on the basal plane for sonication times exceeding two hours. In contrast to the common belief that UILPE is a non-destructive process, ${ }^{[23 b, 45 b, 47,50]}$ these results indicate the existence of defects both in the basal plane and the edge. Therefore, a selection of appropriate conditions of UILPE, like solvents, sonication time or power, is highly recommended. Another important drawback of UILPE, which ultimately hampers its use on the industrial scale is the fact that the majority of solvents employed for UILPE possess a high boiling point and are thus extremely tough to be removed after exfoliation. Because of this reason, the 


\section{WILEY-VCH}

deposition of 2DMs inks produced via UILPE onto plastic substrates is extremely challenging since thermal annealing at high temperatures is required to achieve the complete solvent removal. ${ }^{[51]}$ In particular, the use of NMP as a prime solvent in 2DMs inks results in long drying time and is impractical for the majority of printing technologies. A much better solution would be to exfoliate graphene in a low boiling point solvent such as ethanol, isopropanol, chloroform, etc. However, they fail to meet the aforementioned characteristics of solvents required for the suitable 2DMs exfoliation. As the number of possible solvent mixtures is virtually unlimited, the strategy based on mixed-solvent gives researchers great freedom in designing ideal solvent systems for each specific application. In this context, the library of low-toxic and low-cost solvents with low boiling points for UILPE is infinitely enlarged when extending to common co-solvents. However, the use of such approach supports only comparatively low concentration of 2DMs without stabilization of exfoliated 2D sheets..$^{[52]}$ Nonetheless, O’Neill et al. ${ }^{[50 \mathrm{~d}]}$ demonstrated the exfoliation of graphene at concentration up to $0.5 \mathrm{mg} \mathrm{mL}^{-1}$ in low boiling point solvents such as chloroform and isopropanol (IPA). Graphene flakes of the lateral size of $\sim 1 \mu \mathrm{m}$ and with a thickness of less than 10 layers ( $\leq 5$ layers for isopropanol) have been obtained. In addition, the deposition of graphene flakes into substrates by spray-coating was also investigated. Some aggregation during evaporation of volatile solvents was observed. However, the deposited flakes tend to assemble into features which are thinner than those obtained with flakes deposited with high boiling point solvents. Moreover, the substrate coverage is much greater when using more volatile solvents, predominantly due to faster evaporation.

On the other hand, in order to match the surface tension between solvent and 2DMs, one can add to the liquid either polymers, ${ }^{[12,51]}$ ionic and non-ionic surfactants, ${ }^{[50 \mathrm{~b}, 50 \mathrm{c}, 53]}$ ionic liquids (ILs) ${ }^{[54]}$ organic compounds ${ }^{[45 a, 55]}$ or inorganic salt. ${ }^{[56]}$ In contrast to exfoliation in organic solvent, surfactants and in particular those exhibiting ionic groups can be adsorbed onto the 


\section{WILEY-VCH}

flakes, providing electrostatic repulsion, which prevents reaggregation of $2 \mathrm{D}$ nanosheets and supports higher concentration of stabilized flakes in the liquid environment. ${ }^{[12,15 b]}$ Coleman et $a l$ first proposed the exfoliation of graphene from graphite powder with a concentration of $0.1 \mathrm{mg} \mathrm{mL}{ }^{-1}$ by UILPE in sodium dodecylbenzenesulfonate (SDBS) aqueous solution. ${ }^{[50 \mathrm{~b}]}$ It was pointed out that SDBS cannot be easily removed and the films contained $\sim 35 \%$ SDBS surfactant. Moreover, it was found that the residual surfactants affect also optical and electrical properties of graphene films. In the case of non-ionic surfactants, which typically have a hydrophobic tail and a long hydrophilic part, steric repulsions stabilize exfoliated $2 \mathrm{DMs} .{ }^{[57]}$ One of the best effective non-ionic surfactant for the preparation of graphene dispersions is triblock copolymer Pluronic P-123. ${ }^{[53]}$ It has been demonstrated, that increase in sonication time, from 2 to $5 \mathrm{hrs,} \mathrm{significantly} \mathrm{raised} \mathrm{the} \mathrm{concentration} \mathrm{of} \mathrm{stably} \mathrm{dispersed}$ graphene, from 0.9 to $1.5 \mathrm{mg} \mathrm{mL}^{-1}$.[53]

The polymer can also encapsulate the $2 \mathrm{D}$ flakes enabling a physical separation between the flakes to allow enhanced exfoliation and further stabilization. Furthermore, Li et al. ${ }^{[58]}$ presented one of the most interesting techniques to form inks for printed electronic. ${ }^{[59]}$ The authors prepared graphene dispersion for inkjet printing for electronics purposes. In particular, the procedure involves UILPE of graphene in DMP for $40 \mathrm{hrs}$ followed by the addition of ethyl cellulose (EC) to obtain stable graphene dispersion. After being exchanged by terpineol through a vacuum distillation process, the graphene concentrations were estimated to be $1.2 \mathrm{mg} \mathrm{mL}^{-1}$. Interestingly, Hyun et al. ${ }^{[60]}$ showed that it is possible to obtain the stable graphene dispersion in EC/ethanol/terpineol with concentration up to $80 \mathrm{mg} \mathrm{mL}^{-1}$. The quality of the exfoliated graphene and the conductivity values achieved in various LPE methods as presented in the recent literature are summarized in Table $\mathbf{1 .}$

Coleman's group was the first to extend UILPE towards other 2DMs beyond graphene. ${ }^{[70]}$ It was found that NMP was the most effective solvent for exfoliation $\mathrm{MoS}_{2}$ and $\mathrm{WS}_{2}$ and IPA 


\section{WILEY-VCH}

for exfoliation of h-BN with concentration around $0.3 \mathrm{mg} \mathrm{mL}^{-1}$ and $0.15 \mathrm{mg} \mathrm{mL} \mathrm{g}^{-1}$ and 0.06 $\mathrm{mg} \mathrm{mL} \mathrm{L}^{-1}$, respectively. TEM revealed the existence of 2D flakes consisting of thin nanosheets (Fig.2. e-f). Moreover, it has been demonstrated that this process is also suitable for exfoliation of other TMDs, such as $\mathrm{NbSe}_{2}, \mathrm{TaSe}_{2}, \mathrm{MoSe}_{2}, \mathrm{MoTe}_{2}, \mathrm{NiTe}_{2}{ }^{[70]}$ This exfoliation method made it possible to prepare films of $\mathrm{MoS}_{2}$ and $\mathrm{WS}_{2}$ by vacuum filtration and spraying, with thickness ranging from a few nanometers to hundreds of micrometers. Recently, Kelly et $a l .{ }^{[71]}$ generated TMDs inks for thin-film transistors using UILPE. Towards this end, $\mathrm{WSe}_{2}$, $\mathrm{WS}_{2}, \mathrm{MoS}_{2}$ and $\mathrm{MoSe}_{2}$ crystals have been sonicated in NMP and size selection has been performed to isolate the thinnest nanosheets ( $<6$ layers). To obtain the printable inks the materials were redispersed in IPA with concentration $<0.8 \mathrm{mg} \mathrm{mL}^{-1}$, using solvent-exchange method. In further studies, Coleman's group systematically investigated the role the experimental parameters during the UILPE of $\mathrm{MoS}_{2}$ in NMP including the starting mass, sonication power, sonication time, and centrifugation conditions. ${ }^{[72]}$ The dispersed concentration of $\mathrm{MoS}_{2}$ increased to $\sim 40 \mathrm{mg} \mathrm{mL}^{-1}$ by increasing the sonication time to 200 hrs. The concentration of $\mathrm{MoS}_{2}$ nanosheets scales linearly with the starting $\mathrm{MoS}_{2}$ mass and was maximized for an initial $\mathrm{MoS}_{2}$ concentration of $100 \mathrm{mg} \mathrm{mL}^{-1}$. However, the flakes produced by long-time sonication exhibited small lateral size and broad size distribution as observed previously for graphene dispersions. ${ }^{[47]}$ Furthermore, by controlling the centrifugation process, large-size flakes can be obtained with mean flake lateral size of approximately $2 \mu \mathrm{m}$ and maximum lateral size of $4-5 \mu \mathrm{m}$. Smith et al. ${ }^{[73]}$ exfoliated inorganic layered compounds such as h-BN, TMDs $\left(\mathrm{MoS}_{2}, \mathrm{WS}_{2}, \mathrm{MoTe}_{2}, \mathrm{MoSe}_{2}, \mathrm{NbSe}_{2}, \mathrm{TaSe}_{2}\right)$ in aqueous surfactant solutions (sodium cholate/water mixture). Nonetheless, $\mathrm{MoS}_{2}$ exfoliated in presence of surfactants yielded nanosheets with up to 10 stacked layers, indicating a low degree of exfoliation. Recently, Wang et al. ${ }^{[74]}$ applied thermo-responsive polymeric ionic liquid to assist the direct exfoliation of bulk $\mathrm{MoS}_{2}$ and $\mathrm{h}-\mathrm{BN}$ into SL and FL nanosheets in an 


\section{WILEY-VCH}

aqueous medium. The concentration of exfoliated $\mathrm{MoS}_{2}$ and h-BN nanosheets in suspensions was found to amount to 1.24 and $0.43 \mathrm{mg} \mathrm{mL}^{-1}$, respectively. Morishita et al. ${ }^{[75]}$ achieved highly concentrated boron nitride dispersions by direct exfoliation of bulk hexagonal boron nitrides using ionic liquids (ILs). In particular, 1-butyl-3-methylimidazolium hexafluorophosphate $[\mathrm{bmim}]\left[\mathrm{PF}_{6}\right]$ afforded a highly stable h-BN suspension at concentration (1.9 $\mathrm{mg} \mathrm{mL}^{-1}$ ) containing less than 10 layers. Therefore, the cation $-\pi$ interactions between $[\mathrm{bmim}]\left[\mathrm{PF}_{6}\right]$ and $\mathrm{h}-\mathrm{BN}$ surface $\mathrm{N}$ atoms play the most important role in the h-BN exfoliation, even more important than the matching of their surface energies.

The UILPE approach has been also successfully extended to BP, by using NMP as solvent to produce BP nanosheet dispersion. ${ }^{[43,76]}$ Additionally, other high boiling point solvents ${ }^{[31,77]}$ as well as water ${ }^{[78]}$ or acetone ${ }^{[79]}$ were utilized for UILPE of BP. Recently, Hanlon et al. ${ }^{[31]}$ reported UILPE of BP under ambient conditions in solvents such as N-cyclohexyl-2pyrrolidone (CHP), which stabilizes the BP nanosheets against oxidation, probably due to protection by the solvation shell. However, production of high-quality BP flakes inevitably leads to the formation of small sized flakes $\sim 1 \mu \mathrm{m}^{2}$. Concentrations as high as $\sim 1 \mathrm{mg} \mathrm{mL} \mathrm{m}^{-1}$ can be realized during prolonged sonication $(100 \mathrm{hrs})$. Chen et al. ${ }^{[28]}$ prepared water dispersion of FL BP nanosheets with $0.4 \mathrm{mg} \mathrm{mL}^{-1}$ concentration, which corresponds to a yield of $6.7 \mathrm{wt} \%$. HR-TEM images revealed the presence of good quality nanosheets with orthogonally symmetric structure, without visible impurities or defects (Fig. 2g-h). They suggest that the high stability of BP sheets can be attributed to their intrinsic high crystallinity and high purity, as well as the oxygen-isolated measurement conditions. The results indicated that this BP dispersion is stable enough for further processing, when it is stored in oxygenisolated containers.

It is well known that, some of the extraordinary properties of 2D nanomaterials, such as the electronic bandgap, are strongly layer dependent, especially at their atomically thin limit. ${ }^{[7]}$ 


\section{WILEY-VCH}

The broad size distribution of 2DMs produced by UILPE is one of the main limitation for their application. Moreover, the yield of the SL nanosheets in the exfoliation suspension is low and the lateral size of the produced nanosheets is relatively small because the sonication force breaks down the big nanosheets into small fragments. Furthermore, there are also some disadvantages in using intercalants/stabilizers to assist the UILPE process of 2D nanosheets. The preferable liquid medium for the electronic application is a pure solvent as this does not introduces impurities into the exfoliated 2DMs. Regardless of whether the 2D films are prepared by deposition techniques like drop-casting or spraying, in most of the cases, the resulting films still comprise surfactants, which do not possess any appealing electronic properties; in other words, their presence can be problematic for applications in electronics. A definite downside is that polymers cannot be easily removed from the $2 \mathrm{DMs}$ ' surface after the exfoliation. However, it should be pointed out that the presence of polymers can also be highly beneficial. Polymer adsorbed onto the material surface after exfoliation can allow the tuning of the physical properties of the ink, which can be desirable for printing electronics as they can affect the properties of devices, e.g. by n-doping of $2 \mathrm{D}$ materials-based devices. ${ }^{[80]}$ Semiconducting polymers can also be added before or during the LPE as demonstrated in a recent report on the production of hybrid graphene/semiconducting polymer films. These hybrid films have proven superior field-effect mobility (as compared to the bare organic semiconductor) and improved processability (as compared to the pure $2 \mathrm{D}$ ink). ${ }^{[81]}$

Table 2 and Table 3 list the key variables describing the electronic properties of 2D materials beyond graphene.

\subsection{High-sheer mixing exfoliation (HSE)}

Although UILPE achieves ultrathin 2D nanosheets with concentrations up to $\sim 1 \mathrm{mg} \mathrm{mL}^{-1}$, such quantities are way too small for any real application. To ensure the accomplishment of 


\section{WILEY-VCH}

the step forward from the laboratory to industrial scale production, it is imperative to develop scalable methods to produce large quantities of $2 \mathrm{DMs}$ at low-cost and relatively short time. Towards this end, Paton et al. ${ }^{[17 b]}$ and Liu et al. ${ }^{[86]}$ demonstrated shear force-assisted liquidphase exfoliation (HSE) for producing dispersions of graphene flakes (Fig. 5). In this method, the high-shear mixer consisting of rotor and stator (or rotating blades) was used to generate high shear rates in liquids, to which the layered powders were added. The working mechanisms of the high shear mixer are based on hydrodynamics and can be divided into high shear force, collision effects and jet cavitation. ${ }^{[87]}$ In a high-shear mixer, very high shear rates are achieved in the gap between the rotor and stator and in the holes in the stator. It has been concluded that the graphene exfoliation process is most likely localised in the vicinity of the rotor-stator. ${ }^{[17 b, 88]}$

The Coleman's group developed a simple model that shows the occurrence of exfoliation once the local shear rate exceeds a critical value that was found being $\sim 10^{4} \mathrm{~s}^{-1} \cdot{ }^{[17 b]}$ This allowed graphene to be efficiently exfoliated in NMP up to the hundred-litre scale with production rates exceeding $5.3 \mathrm{~g} \mathrm{hrs}^{-1}$ in $10 \mathrm{~m}^{3}$ yet the concentrations of graphene are relatively low, being ca. $0.07 \mathrm{mg} \mathrm{mL}^{-1}$. Although the HSE allows producing large quantities of inks, the quality of exfoliated material is not extraordinary. In particular, the thickness distribution (1-10 layers) and the lateral size of the flakes $(200-800 \mathrm{~nm})$ suggest that the fragmentation of the flakes occurs much faster than the exfoliation. Importantly, the production rates can indeed be enhanced by increasing the volume, which is an ideal case scenario for scale-up. Interestingly, Liu et al. ${ }^{[86]}$ showed the green alternative to HSE by using IPA-water mixture to exfoliate graphene. The concentration of the graphene dispersion prepared in $40 \mathrm{vol} \%$ IPA-water mixture is about $0.27 \mathrm{mg} \mathrm{mL}^{-1}$ which is far greater than that of prepared in DMF $\left(0.06 \mathrm{mg} \mathrm{mL}^{-1}\right)$. The ideal values of surface tension and the viscosity are 


\section{WILEY-VCH}

important parameters in hydrodynamics and can influence the motion of the liquid layer. Consequently, the best experimental volume fraction was proposed as 40 vol\% IPA-water for preparing graphene nanosheets via the HSE. Electronic properties and quality of high shear exfoliated graphene are presented in Table 1, Section 2.1.

It is not surprising that HSE approach on a number of layered crystals beyond graphene, such as TMDs and h-BN has already been demonstrated (see Table 2. Section 2.1) ${ }^{[17]}$ HSE route was also extended to exfoliate BP bulk crystal into FL nanosheets. ${ }^{[84]}$ After 9 hours $0.04 \mathrm{mg}$ $\mathrm{mL}^{-1}$ suspension was obtained. In this dispersion, nearly $25 \%$ of the sample was SL and the lateral size was similar to the material produced using bath sonication at a smaller scale. All the aforementioned results indicate that HSE is a promising new technology for large scale production of 2DMs that can be processed by using existing industrial technique, such as real-to-real manufacturing. ${ }^{[17 b, 89]}$ Industrial rotating blade stirrer tank reactor can be used for LPE offering a low cost alternative to sonication, in view of the exfoliation efficiency, which is much higher than that in standard sonication or ball milling exfoliation methods. The main advantage of HSE is its simplicity and production of high quality with few defects 2DMs. Nevertheless, HSE provides nanosheet at relatively low concentrations $(<0.1 \mathrm{mg}$ $\mathrm{mL}^{-1}$ ), limiting the efficiency of the process. If high concentrations are required, then better results will be achieved by sonicating at high energy density. However, if high production rate is needed, shear mixing seems to be the only possible solution.

\subsection{Electrochemical exfoliation (EE)}

Electrochemical approaches are becoming more and more popular towards exfoliation of 2DMs and it have drawn increasing attention over the past years as a potentially scalable method. Among them, electrochemical exfoliation (EE) of graphite in both aqueous and organic electrolytes is extensively explored as it can be used to produce graphene flakes of 


\section{WILEY-VCH}

different sizes, thicknesses, and quality. The basic concept of EE relies on the use of intercalating ionic species, which penetrates into bulk 2DMs under an electrochemical bias to drive structural expansion at a graphite electrode. ${ }^{[90]} \mathrm{EE}$ of graphite into graphene - commonly referred to as electrochemically exfoliated graphene (EEG) - can occur either under anodic or cathodic conditions. ${ }^{[16 a]}$ While the anodic exfoliation process can be carried out in the mixture of water and ionic liquids, ${ }^{[91]}$ aqueous solution of inorganic salts or mineral acids, ${ }^{[64 a, 64 b, 90 b, 92]}$ the cathodic method relies on the use of organic solvents (e.g., propylene carbonate (PC), ${ }^{[93]}$ dimethyl sulfoxide (DMSO) $,{ }^{[94]} \mathrm{NMP},{ }^{[95]}$ acetonitrile ${ }^{[96]}$ ) containing lithium or alkylammonium salts.

In the anodic process, the potentials required for the anions to intercalate are usually greater than the potentials needed for graphite oxidation, ${ }^{[16 a]}$ thus anodically exfoliated graphene tend to be significantly oxidized due to the generation of reactive oxygen species from water at the graphite anode. While it is not desirable for the electronic applications, in general extensive oxidation should be avoided. ${ }^{[25]}$ In EE, both the exfoliation time and the type of employed electrolyte can led to the formation of defect-free graphene sheets at high concentrations. ${ }^{[97]}$ To address this issue, researchers have explored some approaches to hamper the oxidation process, e.g. by using specific types of graphite as the anode ${ }^{[98]}$ or inorganic salts instead of acids as the electrolyte, ${ }^{[25,64 b, 99]}$ multifunctional electrolytes ${ }^{[97]}$ and also by performing EE in confined space. ${ }^{[64 d]}$ In anodic process, Liu et al.$^{[100]}$ exfoliated graphite rod using protonic acids like $\mathrm{H}_{2} \mathrm{SO}_{4}, \mathrm{H}_{3} \mathrm{PO}_{4}$ and $\mathrm{H}_{2} \mathrm{C}_{2} \mathrm{O}_{4}$ in the voltage range of 6-8 V. Among these various inorganic acids, sulfuric acid attracts the attention in exfoliation of graphite because the ionic size of $\mathrm{SO}_{4}^{2-}(0.46 \mathrm{~nm})$ is similar to the graphite interlayer spacing $(0.34 \mathrm{~nm})$, which is favourable for the intercalation process. ${ }^{[101]}$ Moreover, electrolysis of sulfate ions and water can lead to the generation of gaseous species such as oxygen, hydrogen and sulfur dioxide and cause the expansion of the interlayer distance of graphite. Su et al. ${ }^{[92 \mathrm{~b}]}$ also examined a library 


\section{WILEY-VCH}

of different electrolyte for the $\mathrm{EE}$ of graphite, including $\mathrm{HBr}, \mathrm{HCl}, \mathrm{HNO}_{3}$ and $\mathrm{H}_{2} \mathrm{SO}_{4}$ and only the electrolytes containing $\mathrm{H}_{2} \mathrm{SO}_{4}$ exhibit ideal exfoliation efficiency, which is consistent with the report of Liu et al. ${ }^{[100]}$ This method allows producing thin graphene sheets, more than $60 \%$ of which are less than $2 \mathrm{~nm}$ in thickness, with a lateral size of $1-40 \mu \mathrm{m}$. In Su's work, ${ }^{[92 \mathrm{~b}]}$ the authors applied a relatively high $(10 \mathrm{~V})$ voltage to graphite anode for the synthesis of graphene sheets. Parvez et al. ${ }^{[64 \mathrm{a}]}$ demonstrated EE of graphite using $0.1 \mathrm{M} \mathrm{H}_{2} \mathrm{SO}_{4}$ and $10 \mathrm{~V}$ for $2 \mathrm{~min}$. The optimized electrolyte concentration produced high yield ( $>80 \%)$ of graphene sheets with 1-3 layers and a lateral size around $10 \mu \mathrm{m}$. It is important to note, that in all known reports where acidic electrolyte has been employed, a significant amount of oxygencontaining functional groups which is due to the strong oxidation of graphite by the acid. ${ }^{[64 a}$, ${ }^{92 b, 100]}$ For this reason, aqueous electrolytes containing inorganic sulfate salts became extremely popular. ${ }^{[25,64 b, 99,102]}$ Parvez et al. ${ }^{[64 \mathrm{~b}]}$ reported the EE of graphite in aqueous inorganic salts, such as ammonium sulfate $\left(\left(\mathrm{NH}_{4}\right)_{2} \mathrm{SO}_{4}\right)$, sodium sulfate $\left(\mathrm{Na}_{2} \mathrm{SO}_{4}\right)$, and potassium sulfate $\left(\mathrm{K}_{2} \mathrm{SO}_{4}\right)$. The obtained graphene sheets showed a high yield of $85 \%$ (1-3 layers) with a lateral size up to $44 \mu \mathrm{m}$ and an oxygen content reduced down to 5.5 atomic $\%$, being lower than that obtained in acidic electrolyte solution (i.e., 7.5 atom \%). ${ }^{[64 a]}$ It was concluded that applying bias voltage results in the reduction of water molecules at the cathode, creating hydroxyl ions $\left(\mathrm{OH}^{-}\right)$that act as a strong nucleophile in the electrolyte. Because of the high chemical reactivity of those species, subsequent nucleophilic attack takes place, where $\left(\mathrm{OH}^{-}\right)$react with the graphite - initially at the edge sites and grain boundaries. While this process takes place in the initial seconds of the EE, it leads to the depolarization and expansion of the graphite layers, thereby facilitating the intercalation of $\mathrm{SO}_{4}{ }^{2-}$ between the graphitic layers. Subsequently, reduction of $\mathrm{SO}_{4}{ }^{2-}$ anions occurs and is accompanied by self-oxidation of water, which produces gaseous species such as $\mathrm{SO}_{2}$ and $\mathrm{O}_{2}$. While EE unavoidably results in the oxidation of graphene nanosheets, the oxygen levels of EEG 


\section{WILEY-VCH}

nanosheets can be easily reduced by employing microwave irradiation - as previously explored for GO reduction. ${ }^{[103]}$ In particular, we recently showed that EEG oxygen percentage decreases from 12 to $7 \%$ upon microwave irradiation. ${ }^{[25]}$ In addition, we have investigated the correlation between the EEG structure and electrical characteristics. AFM images showed that most of the EEG flakes appear damaged and characterized by rough surfaces (Fig. 2a-b). Surprisingly, when MW treatment is performed on EEG films, no noticeable changes in electrical performances are observed before and after MW irradiation Therefore, charge transport within EE graphene is mostly hindered by structural defects rather than by oxygencontaining defects.

Furthermore, not only inorganic sulfate salt can be used for the electrochemical exfoliation of graphite but also organic sulfate and sulfonate salts exhibited promising applications when EE of graphite is carried out. Munuera et al. ${ }^{[97]}$ investigated various molecules incorporating a hydrophobic units ehhibiting with one or several anionic groups. It was proved that sodium sulfate (SS) afforded a large amount of expanded product upon anodic treatment, in agreement with previous results. ${ }^{[64 b,}{ }^{104]}$ Unfortunately, the sulfate salts failed to colloidally stabilize the resulting graphene sheets. On the other hand, homogeneous, opaque black suspensions stable for weeks to months were shown for EE of graphite in disodium naphthalene-1,5-disulfonate (SNDS). EEG dispersion $\left(0.84 \mathrm{mg} \mathrm{mL}^{-1}\right)$ with low (2\%) of oxygen content of graphene flakes was obtained. These results indicate that oxidation of anodically exfoliated graphene can be largely prevented as long as a suitable electrolyte is employed. The same group has confirmed that the type of starting graphite material impacts both the oxygen and defect content of anodically exfoliated graphene obtained thereof. ${ }^{[98]} \mathrm{A}$ comparison between graphene obtained from highly oriented pyrolytic graphite (HOPG), graphite foil, flakes and powder by electrolytic treatment with potassium sulfate was carried out. These results indicated that graphene nanosheets obtained in the same conditions from 


\section{WILEY-VCH}

graphite foil are significantly less oxidized than their HOPG-derived counterparts, which can be a significant information from the scale-up point of view. For the first time, Yang et al. ${ }^{[63]}$ achieved dual EE at both electrodes simultaneously using aqueous solution of organic sulfate salts, mainly TBA $\cdot \mathrm{HSO}_{4}$ as a conductive media. The electrochemical system consisted of two graphite foils as anode and cathode. A scalable exfoliation strategy was showed using five types of graphite foils (10 pieces) in a laboratory trial, producing $5.50 \mathrm{~g}$ EEG within $15 \mathrm{~min}$, with a high yield up to $75 \%$ (1-3 layers). A homogeneous dispersion $\left(0.10 \mathrm{mg} \mathrm{mL}^{-1}\right)$ of graphene nanosheets in DMF was obtained. Graphene-derived materials is often characterized by the changes in the ratio of the $\mathrm{D}\left(1350 \mathrm{~cm}^{-1}\right)$ and $\mathrm{G}\left(1600 \mathrm{~cm}^{-1}\right)$ bands areas on the Raman spectrum. ${ }^{[105]}$ In fact, $\mathrm{I}_{\mathrm{D}} / \mathrm{I}_{\mathrm{G}}$ is commonly used to quantify the disorder level in graphene. The authors produced graphene with the low value of the $\mathrm{I}_{\mathrm{D}} / \mathrm{I}_{\mathrm{G}}=0.16,{ }^{[63]}$ which revealed low level of defects and high quality graphene sheets, being superior to EEG produced under anodic conditions from aqueous electrolytes $(0.25-0.4) \cdot{ }^{[64 a, 64 b]}$ On the other hand, the oxygen content of graphene sheets was calculated to be 4.5 atom $\%$ and $\mathrm{C} / \mathrm{O}$ ratio of 21.2 , being higher than values reported previously. ${ }^{[64 a, 64 b]}$ Yang et al. ${ }^{[64 c]}$ studied the radical assisted EE of graphite in the presence of a series of antioxidants in a neutral aqueous electrolyte ammonium sulfate. Remarkably, (2,2,6,6-tetramethylpiperidin-1-yl)oxyl TEMPO suppresses the formation of radicals (e.g., $\mathrm{HO}^{*}$ ) from water electrolysis, which disrupt the graphitic structure during the EE process. ${ }^{[64 a, 90 a, 106]}$ The exfoliation mechanism predict the reaction of $\left(\mathrm{HO}^{\circ}\right)$ radicals with the surrounding TEMPO radicals (nitroxides) to form metastable intermediates (e.g., TEMPO-OH), which are converted to oxoammonium cations. In the next step, the oxoammonium cations can be electrochemically reduced at the cathode, forming pristine TEMPO radicals. ${ }^{[107]}$ In addition, the electrolysis of sulfate ions and water resulted in evalution of gaseous species such as oxygen and sulfur dioxide and caused expansion of the interlayer distance of graphite layers. ${ }^{[64 b]}$ Therefore, the high quality graphene flakes with the 


\section{WILEY-VCH}

low oxygen content (as low as 3.8\%) and a yield of $75 \mathrm{wt} \%$ has been achieved. ${ }^{[64 \mathrm{c}]}$ The EEG sheets were large in size, ranging from 5 to $10 \mu \mathrm{m}$. Moreover, re-dispersion EEG nanosheets in DMF allowed formation of stable dispersions at the concentration of ca. $6 \mathrm{mg} \mathrm{mL}^{-1}$. In addition, Wang et al.$^{[64 d]}$ designed an approach for the electrochemical exfoliation of graphite in confined space (EECS) so as to prevent the graphite sheets from prematurely peeling off from the graphite electrode using paraffin wax and promote the sufficient intercalation of electrolyte ions. Strong alkaline electrolyte $\left(10 \mathrm{~mol} \mathrm{~L}^{-1} \mathrm{NaOH}\right)$ under a low voltage of $3 \mathrm{~V}$ was used, so as to prepare graphene with decreased amounts of defects $\left(\mathrm{I}_{\mathrm{D}} / \mathrm{I}_{\mathrm{G}}=0.26\right)$ and an increased yield ( $60 \%,<5$ layers graphene). Ozone generated during electrochemical process can form holes in the graphene sheets, which is additionally accelerated when the electrolytic voltage increases.

The quality of the exfoliated graphene and the conductivity values achieved in EE described in this section are summarized in Table 1, Section 2.1.

Similarly to other LPE approaches, the electrochemical exfoliation can be employed for other 2DMs, e.g. bulk $\mathrm{MoS}_{2}$ can be electrochemically exfoliated in ionic electrolyte e.g. $\mathrm{Na}_{2} \mathrm{SO}_{4}$ solution. ${ }^{[16 b]}$ In anodic process, the lateral size of as-produced SL and FL MoS ${ }_{2}$ nanosheets can reach $50 \mu \mathrm{m}$. The $\mathrm{MoS}_{2}$ nanosheets were redispersed in NMP, however with a low concentration of $0.014 \mathrm{mg} \mathrm{mL}^{-1}$ and a yield of $\approx 9 \%$. Most of the synthesized nanosheets were FL (70\% of them comprised 2-5 layers) instead of well-dispersed SL nanosheets. The Raman spectra showed the high quality of the exfoliated $\mathrm{MoS}_{2}$ nanosheets. You et al. ${ }^{[83]}$ introduced EE method to produce SL or FL MoS 2 semiconducting nanosheets in sulfuric acid solution. The exfoliated $\mathrm{MoS}_{2}$ sheets exhibited lateral size up to $20 \mu \mathrm{m}$. A mechanism of the process, similar to the one of graphite $\mathrm{EE}^{[64 b]}$ was proposed. ${ }^{[83]}$ This intercalation process led to the formation of gaseous $\mathrm{SO}_{2}$ or $\mathrm{O}_{2}$ gas bubbles between adjacent layers and exfoliates $\mathrm{MoS}_{2}$ nanosheets from the bulk $\mathrm{MoS}_{2}$ crystal. 


\section{WILEY-VCH}

Black phosphorus (BP) can also be exfoliated using EE method (Table 3, Section 2.1). In recent study, $\mathrm{BP}$ was obtained from bulk BP in acidic and $\mathrm{Na}_{2} \mathrm{SO}_{4}$ electrolyte solutions in anodic conditions. ${ }^{[85 \mathrm{a}, 108]}$ Ambrosi et al. ${ }^{[108 \mathrm{a}]}$ proposed electrochemical exfoliation method in aqueous solution of $\mathrm{H}_{2} \mathrm{SO}_{4}$ to produce FL sheets of BP starting from bulk crystals.

Unfortunately, oxide layers on the surface could not be avoided due to the fact that BP is highly unstable in open air ${ }^{[109]}$ and the oxidation process is favoured by the anodic exfoliation method itself. Zheng et al. ${ }^{[108 b]}$ obtained 2-4 layers of non-oxidized BP, during the intercalation and electrochemical exfoliation process of $60 \mathrm{~min}$ in $\mathrm{Na}_{2} \mathrm{SO}_{4}$ solution. The entire process was conducted at a constant voltage of $-8 \mathrm{~V}$ for the intercalation of the $\mathrm{Na}^{+}$ions between $\mathrm{BP}$ layers, since $\mathrm{Na}^{+}$has been proposed to be a reliable intercalant of $\mathrm{BP}$ to form $\mathrm{Na}_{3} \mathrm{P} \cdot{ }^{[110]}$

In comparison, cathodic exfoliation of 2DMs in a non-aqueous system would not suffer from oxidation and can offer an alternative approach towards production of non-oxidized nanosheets with high quality. Thus, cationic EE may be an alternative approach to produce the 2DMs for electronic application. Zhou et al. ${ }^{[111]}$ prepared FL graphene by EE of a graphite cathode using $\mathrm{Na}^{+} / \mathrm{DMSO}$ complexes as the intercalant and thionin acetate salt as stabilizer. Raman spectra indicated that the graphene material had lower content of defects.

Nevertheless, the oxygen content on the surface of graphene was not lower than in anodic EE. ${ }^{[25,64 b]}$ The electrochemical intercalation of tetraalkylammonium (TTA) cations was reported to produce graphene dispersion. ${ }^{[95,112]}$ However, the very low concentration $(0.01 \mathrm{mg}$ $\mathrm{mL}^{-1}-0.04 \mathrm{mg} \mathrm{mL}^{-1}$ ) exclude this method to produce graphene for practical application. Furthermore, the cathodic EE of BP nanosheets was attempted via the intercalation of cations into BP layers. Recently, TTA intercalation was widely investigated in EE of bulk BP. ${ }^{[85 b-d,}$

${ }^{113]}$ Huang et al. ${ }^{[85 \mathrm{~d}]}$ proposed cathodic EE method via controlling the intercalation rate of TTA cations to prepare BP nanosheets. It was obtained various layers (from 2 to 11) of BP 


\section{WILEY-VCH}

using tetrabutylammonium hexaflorophosphate (TBAP) in DMF solution. The voltage adopted in the exfoliation process was $-5 \mathrm{~V}$. During 30 min process tiny flakes separating from bulk BP were obtained where the slight oxidization assigned to the partial degradation of $\mathrm{BP}^{[114]}$ were observed. Li et al. ${ }^{[85 b]}$ reported cathodic expansion of $\mathrm{BP}$ in the non-aqueous electrolyte of different TTA salts. It was proved by using in situ CV measurements that around $-3.5 \mathrm{~V}$ the intercalation of TAA cations into the interlayer space of BP was occurred. When potential decreased below $-4 \mathrm{~V}$, the electrochemical decomposition of $\mathrm{DMSO}^{[115]}$ and TAA ions ${ }^{[116]}$ produces gaseous species such as dimethyl sulfite and alkane, resulting the expansion of bulk BP. The influence of the size of cations on exfoliation efficiency was investigated. Tetrabutylammonium tetrafluoroborate (TBAB) turned out to be the most valuable, which results in the production of high-quality BP flakes (average thickness $\sim 5$ layers, lateral area $\sim 10 \mu \mathrm{m}^{2}$ in average) with ultrahigh yield (> 80\%), which is significantly higher than that produced by another LPE methods. ${ }^{[28,31,84]}$ DMSO with a high boiling point can effectively protect as-exfoliated BP sheets from being attacked by $\mathrm{O}_{2}$ during air exposure. The BP nanosheets can be readily re-dispersed in various solvents ranging from non-polar (e.g., toluene, chloroform), polar protic (e.g., $\mathrm{H}_{2} \mathrm{O}$, acetic acid, IPA, dichloromethane) to polar aprotic (e.g., ethyl acetate, acetone, acetonitrile) solvents with the mild sonication (100 W for 1-3 minutes). The dispersion in low-boiling solvents such as IPA with a concentration of $2 \mathrm{mg}$ $\mathrm{mL}^{-1}$ can form inks for use in large-area inkjet printing on a wide range of substrates. Recently, Yang et al..$^{[85 c]}$ used PC and TAA cations to electrochemical exfoliate bulk BP crystal. The cathodic intercalation of TAA cations under ambient conditions hindered formation of defects in the BP flakes, leading to a high exfoliation yield (up to $78 \%$ ) and a large lateral dimension of exfoliated flakes (up to $20.6 \mu \mathrm{m}$ ). Moreover, the PC as a solvent stabilized the exfoliated nanosheets against reaggregation. The same concept as Li et al. ${ }^{[85 b]}$ 


\section{WILEY-VCH}

was proved that TBA cation was the most effective thanks to the size and flexibility of n-butyl chains. The most relevant results reported so far are listed in Table 3, Section 2.1).

EE has recently emerged as a promising approaches for producing 2DMs, most notably graphene, yet, with increasing attention being paid to TMDs an BP with high efficiency and at low cost. ${ }^{[90 \mathrm{a}]}$ In contrast to sonication or shear mixing routes which are typically run over periods of several days, ${ }^{[47,50 c, 72]}$ EE can be performed on the order of minutes or hours. Furthermore, the production yield of SL to FL 2D flakes is much greater than using UILPE, which can produce relatively low fraction (ca. 30\%) of SLs. Anodic EE gives excellent production rate, exceeding $10 \mathrm{~g} \mathrm{hrs}^{-1[64 \mathrm{~b}]}$ to $20 \mathrm{~g} \mathrm{hrs}^{-1} .^{[63]}$ Anodic exfoliation dominate the literature. However, electrolysis in aqueous solution affects the oxidation degree of the produced material, which is not desired outcome for electronic applications. On the other hand, the oxidation degree of anodically exfoliated graphene can be controlled (minimized) by means of some process variables (e.g., type of starting material). ${ }^{[98]}$ Cathodic exfoliation of 2DMs in a non-aqueous system offers an alternative for the isolation of high-quality nonoxidative 2D flakes. The cathodic EE efficiency is controlled not only by the cathodic potential but also by the size of the solvated cations such as tetrabutylammonium cations (TTA). By choosing an appropriate TTA cation, bulk material can be rapidly expanded in the organic electrolyte within several minutes. ${ }^{[85 b, 85 c]}$

\subsection{Ball milling- assisted exfoliation}

Ball milling, a common technique employed in powder production industry, has been successfully used in preparation of FL thick graphite nanosheets (Table 1, Section 2.1). ${ }^{[20,65 \text {, }}$

${ }^{117]}$ In the milling process the 2DMs' particles are stressed between the milling balls. Consequently, compressive and shear forces act on the particles and can lead to a 


\section{WILEY-VCH}

delamination of thin sheets. During the thinning process, the low energy ball milling does not cause significant damage to the in-plane structure of 2D nanosheets and generates fewer defects and impurities, in contrast to EE and UILPE. ${ }^{[117 \mathrm{c}]}$ Long time milling at a low speed ensures the domination of shear forces, which is highly desired for achieving large-size 2D sheets. ${ }^{[117 \mathrm{c}]}$ Moreover, it minimizes the collision or compressive impacts, thereby limiting the fragmentation of large flakes into small ones and improving the quality of the ball milling products. Nonetheless, the concentration of inks produced via ball-milling in solvents like DMF, NMP, THF is relatively low and typically do not exceed $0.1 \mathrm{mg} \mathrm{mL}^{-1} .^{[117 \mathrm{c}]} \mathrm{In} 2010$, Knieke et al. ${ }^{[117 \mathrm{~b}]}$. and Zhao et al..$^{[65 \mathrm{a}, 117 \mathrm{c}]}$ used both stirred media mill and planetary ball mill to achieve the exfoliation of graphite to SL and FL graphene. After these initial works, the research on producing graphene by ball milling is prospering. Recently, Teng et al. ${ }^{[65 \mathrm{e}]}$ developed effective route to construct ultrahigh conductive graphene paper by preparing graphene dispersion in NMP at high yield through ball milling and subsequently fast filtration, thermal treatment and mechanical compression. The calculated graphene concentration in supernatant was as high as $2.6 \mathrm{mg} \mathrm{mL}^{-1}$. In the case of wet or dry ball mills, the introduction of exfoliating agent (solvents ${ }^{[65 \mathrm{e}]}$ or solids ${ }^{[65 \mathrm{~d}]}$ ) are essential to avoid reaggregation of 2D flakes and increase the exfoliation degree. Non-covalent interaction assisted ball milling, especially $\pi$ - $\pi$ interaction between aromatic molecules (melamine, triazines, pyrene) and the surface of graphite, led to the faster exfoliation and production high quality graphene. ${ }^{[20,65 b, 118]}$ Ding et al. ${ }^{[24]}$ developed an effective method to formation an ultrahigh thermal conductive graphene flexible paper by ball milling technique in the presence of sodium lignosulfonate, which enabled to exfoliate SL and FL graphene from natural graphite (Fig. 2d). As a result, high concentrated graphene dispersion exhibited excellent film formation ability. 


\section{WILEY-VCH}

On the other hand, hitherto very little research has been conducted on layered crystals beyond graphene with this technique. ${ }^{[119]}$ In particular, Yao et al. ${ }^{[120]}$ used a combination of planetary ball milling and ultrasonication to exfoliate both h-BN and $\mathrm{MoS}_{2}$. These fabricated 2D nanosheets can be well dispersed in aqueous solutions at concentrations, $1.2 \mathrm{mg} \mathrm{mL}^{-1}$ and 0.8 $\mathrm{mg} \mathrm{mL}^{-1}$ for h-BN and $\mathrm{MoS}_{2}$, respectively. It has subsequently been shown that ball milling in stirred media mills can indeed be used to exfoliate $\mathrm{MoS}_{2}$ and $\mathrm{WS}_{2}$ without using additional production techniques. ${ }^{[119 \mathrm{c}]}$ The preparation of FL h-BN with a thickness around $2.5 \mathrm{~nm}$ and lateral dimensions mostly below $100 \mathrm{~nm}$ by solid-state ball milling of commercially available h-BN and urea powder was reported by Lei et al. ${ }^{[119 a]}$ It was shown that the urea not only assists the exfoliation but also protects the h-BN from excessive mechanical damage, preventing an extensive formation of lattice defects.

Notwithstanding the drawbacks, ball milling process has attracted much attention and inspired numerous researchers because of its promising results and potential scientific values.

Moreover, ball milling technique is very interesting method from the industrial point-of-view. Nevertheless, since the collision among grinding media cannot be prevented during the milling process, the fragmentation and defects are unavoidable. Compared to UILPE or EE, exfoliation by ball milling is a rather premature technique that requires further studies and optimization of process parameters (stirrer rotation speed, delamination tool and media size) to demonstrate its broader applicability.

\subsection{Microfluidization}

Microfluidization represents one among many high pressure homogenization approaches, which have found a wide range of application in pharmaceutical and food industries. ${ }^{[121]}$ The working principal of microfluidization relies on passing the fluid under high pressure (up to $207 \mathrm{MPa}$ ) through micro channels (diameter, $\mathrm{d}<100 \mu \mathrm{m}$ ) into an interaction chamber. ${ }^{[19]}$ The 


\section{WILEY-VCH}

exfoliation process occurs as a result of turbulence, cavitation and shear effects that occur during the passage through the microfluidizer. In contrast to UILPE and HSE, in which shear rates are localized in the rotor-stator gap, in microfluidization high shear rate $\left(>10^{-6} \mathrm{~s}^{-1}\right)$ is applied to the whole fluid volume due to the passing through microchannel. ${ }^{[19]}$ Recently, it was demonstrated that the use of microfluidizer allows the production of FL graphene directly from natural flake graphite (Table 1, Section 2.1). ${ }^{[19,66]}$ Karagiannidis et al. ${ }^{[19]}$ designed microfluidization in a cyclic process flow, making the procedure highly scalable for graphite exfoliation. The quality of graphene nanosheet obtained at different processing cycles (from 5 to 100 cycles) was investigated. Lateral size of the flakes decreased with increasing in number of passes through the microfluidizer. After 100 cycles, the mean flake lateral size was measured as $\sim 1 \mu \mathrm{m}$ and thickness distribution of the flake between 4 and $70 \mathrm{~nm}$ with the maximum number of flakes at $\sim 7.4 \mathrm{~nm}$. Additionally, excessive oxidation does not occur during microfluidization. The oxygen content was estimated between $2 \%-5 \%$. The analysis of the intensity ratio of the $\mathrm{D}$ to $\mathrm{G}$ peaks on the Raman spectra for $20-70$ cycles did not show a significant difference with respect to the starting graphite. However, for 100 cycles a more disordered material with edge- and basal-plane defects was observed. Therefore, the sample after 70 cycles was selected to formulate conductive printable graphene inks.

Microfluidization has proved to be highly efficient in the exfoliation of graphite and even this method is not widely used, it is a very promising technique for the exfoliation of other layered materials.

\subsection{Solvothermal assisted liquid-phase exfoliation (SALPE)}

Solvothermal assisted liquid-phase exfoliation (SALPE) is another method to exfoliate layered materials, yet it is rather uncommon. The process involves the use of a solvent under various pressures and temperatures through complicated procedures and by means of specific 


\section{WILEY-VCH}

equipment such as autoclave. Such characteristics render SALPE not very interesting from the industrial point-of-view. SALPE requires time-consuming post-treatments of the exfoliated materials, such as long ultrasonication and therefore has the same disadvantages as UILPE, e.g., limit the size and yield of thin graphene layers. ${ }^{[12]}$ However, there are some examples of using SALPE to produce graphene directly from graphite. ${ }^{[18,69 a, 122]}$ The most relevant results reported so far are listed in Table 3, Section 2.1. In 2009, Qian et al. ${ }^{[18]}$ showed that SL and bilayer graphene could be produced by a SALPE process in ACN at high temperature of $180^{\circ} \mathrm{C}$ and pressure of $1.1 \mathrm{MPa}$. After centrifugation, the yield of graphene nanosheets (thickness: $0.5-1.2 \mathrm{~nm}$ ) was as high as $10 \mathrm{wt} \%$. A significant variation was developed with a solvothermal process using oleyl amine as a solvent and intercalating reagent for exfoliation of graphite. ${ }^{[67,123]}$ Zheng et al. ${ }^{[67]}$ combined many strategies such as acid pre-intercalationsolvothermal exfoliation and ultrasonication dispersion to achieve concentration of graphene $\left(0.15 \mathrm{mg} \mathrm{mL}^{-1}\right)$ with large flake size (lateral dimension $4 \mu \mathrm{m}$ and areal dimension $300 \mu \mathrm{m}^{2}$ ) of which $80 \%$ were SL. The high temperature and pressure induced by solvothermal treatment may have facilitated the exfoliation. The quality of the flakes was examined by Raman spectroscopy, which showed oxide defects at the edges of the flakes. The contamination from oleyl amine could easily be removed by thermal annealing. In addition, XPS analysis gave the atomic percentages of oxygen $2 \%$ for the large-flake film and $4 \%$ for the small-flake film and $0.5 \%$ of nitrogen after annealing. SALPE followed by simple microwave irradiation was also used to exfoliate graphene. Khai et al. ${ }^{[69 \mathrm{~b}]}$ obtained FL graphene during $72 \mathrm{hrs}$ at $250{ }^{\circ} \mathrm{C}$ starting from commercial expanded graphite. The graphene flakes had a lateral size of 3-10 $\mu \mathrm{m}$ and low oxygen $(6.5 \%)$ content. $^{[124]}$ Park et al. ${ }^{[68]}$ introduced eutectic based method for fabrication of high-quality graphene flakes. The mixture of intercalated salts $(\mathrm{KCl}, \mathrm{NaCl}$, $\left.\mathrm{ZnCl}_{2}\right)$ and pristine graphite were heated in autoclave vessel $\left(10 \mathrm{hrs}, 210-350{ }^{\circ} \mathrm{C}\right)$. Then, 


\section{WILEY-VCH}

graphene flakes were dispersed in pyridine to improve the exfoliation (after $24 \mathrm{hrs}, 60 \%$ yield) and to enable a stable dispersion ( $>6$ months).

In recent study, Huang et al. ${ }^{[125]}$ demonstrated liquid phase exfoliation of $\mathrm{MoS}_{2}$ assisted by formamide solvothermal treatment. Bulk $\mathrm{MoS}_{2}$ was pre-treated in formamide in an autoclave for $48 \mathrm{hrs}$ at different temperatures of $120-140{ }^{\circ} \mathrm{C}$. Afterwards, the mixture was sonicated for $3 \mathrm{hrs}$ with NMP as SALPE solvent. The high concentrations estimated was $\sim 0.21 \mathrm{mg}$ $\mathrm{mL}^{-1}$. The exfoliated $\mathrm{MoS}_{2}$ nanosheets were less than or equal to $0.9 \mathrm{~nm}$ in thickness, which is a little larger than of the theoretical value $(0.65 \mathrm{~nm})$ in single layer regime. The lateral size of the nanosheets mostly ranged about $40 \mathrm{~nm}$. Recently, the acetonitrile SALPE technique was proposed by Yan et al. ${ }^{[126]}$ to produce FL BP nanosheets with the lateral size up to $10 \mu \mathrm{m}$ with a thickness of $2 \mathrm{~nm}$. After ACN intercalation under solvothermal conditions $\left(200^{\circ} \mathrm{C}\right.$ for $24 \mathrm{hrs}$ ), the resulting solution was sonicated for an hour. The XRD results indicated that ACN is an effective solvent to weaken the van der Waals forces and further realize the effective exfoliation of bulk BP in SALPE.

In this sub-chapter, we have highlighted the recent development on the liquid-phase exfoliation of 2DMs from their bulk counterparts by using a variety of LPE methods. It has to be noted, that like any other processing method, LPE has various advantages when compared to other top-down production methods of 2DMs, yet, there are several major drawbacks which have to be considered. LPE is versatile and potentially up-scalable approach to produce high quality inks at relatively low price, nevertheless, as-produced nanosheets exhibit broad thickness and lateral size distributions, ${ }^{[29]}$ especially when the most common technique such as UILPE and HSE are used. Extensive effort has been made to improve the yield of exfoliation, yet, the yield of single-layer 2D sheets is still relatively low and requires long lasting sonication treatments, which also severely reduced size of the flakes and affect the 


\section{WILEY-VCH}

quality of nanosheets. ${ }^{[47]} \mathrm{HSE}$ is a promising technology for large scale production of 2DMs with high production rate, yet, relatively low concentrations $\left(<0.1 \mathrm{mg} \mathrm{mL}^{-1}\right)$ limit the efficiency of the process. Among LPE approaches, EE is attracting more and more attention as it allows production of relatively large (up to $10 \mu \mathrm{m}$ in lateral size) good quality SL and FL nanosheets. Electrochemical methods have been demonstrated by a number of research groups to produce 2D flakes in milligram and gram quantities. ${ }^{[63,85 \mathrm{~b}, 85 \mathrm{c}]}$ Finally, microfluidization has appeared lately as an interesting alternative for well-established LPEbased. ${ }^{[19]}$ This technique seems to be very promising from the industrial point-of-view and after further studies can be a widely used for LPE of 2DMs. Over the past few years both EE and very recently microfluidization have been identified as suitable candidates to replace UILPE for scalable layered materials exfoliation and both hold potential to be employed at the industrial scales. Besides LPE techniques presented above, alternative approaches are still emerging. In particular, Bonaccorso et al. has recently demonstrated a novel approach developed for the LPE of graphite, $h$-BN and TMDCs. The process is based on high-pressure wet-jet-milling (WJM), resulting in a $2 \mathrm{~L} \mathrm{~h}^{-1}$ production of $10 \mathrm{~g} \mathrm{~L}^{-1}$ of SL and FL flakes in dispersion making the scaling-up more affordable. ${ }^{[127]}$

\section{Patterning of 2D inks into functional structures for electronic applications}

2DMs possess numerous exceptional mechanical and optical characteristics making them suitable for a wide range of applications. Additionally, they exhibit highly diverse and welldefined electronic properties as they can be metals, semimetals, insulators and semiconductors with direct and indirect band gaps ranging from ultraviolet to infrared throughout the visible range. Nevertheless, the exploitation of such properties requires the patterning of the materials onto a wide variety of rigid or flexible substrates. ${ }^{[51]}$ Hence, numerous coating techniques have been adapted to control the patterning of surfaces with 


\section{WILEY-VCH}

LPE dispersions in order to take advantage of the mechanical and opto-electrical characteristics of the selected 2D ink. ${ }^{[128]}$ The well-established deposition techniques used for 2D inks deposition are illustrated in Figure 6 and include spray-coating, spin-coating, dropcasting, dry-transfer, inkjet printing, Langmuir Blodgett (LB), Langmuir Schaefer (LS) and roll-to-roll (R2R) processing. These techniques differ greatly in terms of resulting film morphology, ease of processing and process scalability.

2DMs produced through LPE can be electrically characterized upon deposition on various rigid or flexible substrates. The standard electrical characteristics of conductive layers, i.e. the conductivity and the sheet resistance, can be probed through the fabrication of 2-terminal devices. The electrical characteristics of semiconducting films, i.e. the field-effect mobility $(\mu)$, on-to-off current ratio $\left(\mathrm{I}_{\text {on }} / \mathrm{I}_{\text {off }}\right)$ and threshold voltage $\left(\mathrm{V}_{\text {th }}\right)$ are typically tested through the fabrication of three-terminal devices, i.e. field-effect transistors. ${ }^{[129]}$ In both cases, the extracted characteristics include resistance contributions from both the active material (in the channel between source and drain electrodes) and the electrode-active material contacts. Since the contribution of the contact resistance might be high compared to the channel resistance (particularly in short-channel devices), 2- and 3-terminal devices may prove inadequate to extract electrical characteristics. The separation of current and voltage electrodes in 4-probes measurements circumvent the issue and allow precise measurements of the sheet resistance/mobility, ${ }^{[130]}$ but result in increased fabrication and testing complexity.

The electronic devices based on LPE processed sheets typically have an inferior performance to those made from MME or CVD 2DMs. In fact, such behaviour is not surpassing since MME or CVD sheets typically have a higher quality than LPE materials. Furthermore, the domain sizes of CVD-grown 2D materials are usually larger than LPE 2DMs, leading to fewer junctions in the channels and improved performances. Although the semiconducting and metallic 2DMs for electronic applications are generally produced via 


\section{WILEY-VCH}

LPE with good crystal quality, their mobilities are several orders of magnitude lower than MME or CVD grown samples. In particular, room temperature charge carrier mobilities of MME can be as high as $1.5 \times 10^{4} \mathrm{~cm}^{2} \mathrm{~V}^{-1} \mathrm{~s}^{-1},{ }^{[131]}$ whereas charge carrier mobilities of LPE graphene are reported between 1-100 $\mathrm{cm}^{2} \mathrm{~V}^{-1} \mathrm{~s}^{-1}$ (which will be discussed in detail in this chapter). Furthermore, charge carrier mobilities of semiconducting 2DMs typically range from $10^{3}$ to $10^{4} \mathrm{~cm}^{2} \mathrm{~V}^{-1} \mathrm{~s}^{-1}$, which may be greatly reduced to $1 \mathrm{~cm}^{2} \mathrm{~V}^{-1} \mathrm{~s}^{-1}$ for films assembled from LPE 2DMs. As aforementioned, this can be explained by the fact that 2DMs produced via LPE methods result in sheets exhibiting certain level of structural modifications, as well as altered electronic properties caused by solvent residuals, and re-stacking of the exfoliated sheets. Despite these disadvantages, it has to be pointed out that it is extremely difficult to synthesize inch-size single crystal or homogenous polycrystalline 2D semiconductors by CVD, while production of inch-size (or larger) films using LPE 2DMs is very simple - as discussed in this chapter. Therefore, LPE 2DMs hold great potential for electronic applications, particularly for low-end applications which do not require high carrier mobilities and $\mathrm{I}_{\mathrm{on}} / \mathrm{I}_{\mathrm{off}}$ ratios.

The large number of 2DMs and the various deposition techniques being complemented by a vast array of applications and sought-after opto-electronic properties, that have been produced by many researchers result in a large body of an inhomogeneous bibliography, making the benchmarking of electrical performances between fabricated devices nearly impossible. Furthermore, it is particularly noteworthy stressing that while the ultimate goal of 2D inks formation is the production of thin-films, some groups report their findings on a chosen single flake device. Unfortunately, such practices are often resulting in data biased towards higher performance and do not provide any information of the electronic properties of the films - defeating the purpose of 2D-inks in terms of large area fabrication and processing ease as compared to mechanically exfoliated materials. While electrical 


\section{WILEY-VCH}

measurements on films provide insights into the charge transport within flakes, at flake boundaries as well as flake-to-flake contacts, single flake measurements completely disregard intersheet junction resistances. Furthermore, the consideration of the density of intersheet connections is essential for hybrid 2D materials film characterization, ${ }^{[132]}$ and can only be probed through measurements on a film. Reports on single flakes remain however very useful as they offer information on the quality of the produced inks as compared to mechanically exfoliated 2D crystals.

The operating principles and related advantages and disadvantages of each deposition method are presented in this section. Each described deposition method is accompanied by multiple examples of 2D materials inks used for opto-electronic applications.

\subsection{Drop-casting}

Drop-casting of 2D inks consists of applying a drop of the 2DMs dispersion onto the surface of rigid or flexible substrate, and subsequently allowing the solvent to evaporate, resulting in the formation of a thin-film. Additionally, a final thermal annealing step is often needed to remove residual solvent. ${ }^{[133]}$ The substrate coverage and the morphology of the film resulting from drop-casting is heavily dependent on the drying-up process, ${ }^{[134]}$ as exemplified by the coffee ring effect that has garnered considerable interest by the community. ${ }^{[135]}$ This effect arises when a drop of an ink containing dispersed particles evaporates on the surface of a substrate, leaving a dense deposit along its perimeter. Deegan et al. ascribed this characteristic pattern to a form of capillary flow in which pinning of the contact line of the drying drop ensures that liquid evaporating from the edge is replenished by liquid from the interior. ${ }^{[134,}$ ${ }^{135 c]}$ Therefore, accurate planning of the drop-casting process is crucial in order to form a uniform film. Although drop-casting is a process with a potentially low waste of 


\section{WILEY-VCH}

nanomaterials, solvent and substrate must be carefully selected to obtain a uniform and controlled morphology of the deposited nanomaterials on the substrate surface. ${ }^{[136]}$ Drop-casting has been used for the deposition of various 2D inks such as graphene, ${ }^{[137]}$ $\operatorname{TMDs}^{[72,138]}$ and $\mathrm{BP}^{[77,79]}$ owing to the simplicity of the method. UILPE in organic solvents with or without stabilizer agent, ${ }^{[72,77,79,137 a, 137 b, 138]}$ UILPE in water with addition of surfactant ${ }^{[137 c, 137 \mathrm{~d}]}$ and salt assisted UILPE, ${ }^{[137 e]}$ have been used to produce dispersions of 2DMs suitable for drop-casting deposition.

Erande et al. ${ }^{[85 a]}$ have demonstrated successful drop-casting of a black phosphorus nanosheets dispersion in ethanol on interdigitated Au electrodes geometry followed by the annealing of the device in Argon (Ar) for $2 \mathrm{hrs}$ at $200{ }^{\circ} \mathrm{C}$. The resulting device featured good performances $\left(\mu=7.3 \mathrm{~cm}^{2} \mathrm{~V}^{-1} \mathrm{~s}^{-1}\right.$ and $\left.\mathrm{I}_{\mathrm{on}} / \mathrm{I}_{\mathrm{off}}=10^{4}\right)$ and could be used both as a humidity sensor and a photodetector. However, achieving uniform films through the drop-casting of 2D inks is more challenging since the solvents used for LPE of 2DM typically have high boiling points, which results in a re-aggregation of the flakes when the drop-casting method is used. Therefore, alternative strategies such as spin-controlled drop-casting ${ }^{[1376]}$ or ultrasonic substrate vibration-assisted drop-casting ${ }^{[139]}$ were developed to improve the quality of the deposited film. In the case of ultrasonic substrate vibration-assisted drop-casting, ${ }^{[139-140]}$ the drop-cast dispersion is exposed to unidirectional sound waves, resulting in a 3-fold reduction of the roughness of graphene-doped PEDOT:PSS films. We have demonstrated spin-controlled drop-casting process, ${ }^{[137 b]}$ which was developed to produce uniform highly conductive and transparent graphene films. First the drop is applied to the substrate when the latter is in its planar configuration. The solvent evaporates during back-and-forth rotation of the $\mathrm{x}$-axis by a software-controlled stepper motor at controlled speed and angles. This technique enables to generate homogeneous films, with field-effect mobilities, extracted from the transfer curves, ranging between 0.3 and $1 \mathrm{~cm}^{2} \mathrm{~V}^{-1} \mathrm{~s}^{-1}$. 


\section{WILEY-VCH}

\subsection{Spin-coating}

Spin-coating is ubiquitous within the electronics industry. It is used for the coating of substrates with a wide range of materials, including photoresists, insulators, organic semiconductors, metal and metal oxide precursors, as well as transparent conductive oxides. $^{[133]}$ Therefore, significant efforts in recent years were devoted towards applying this technique as a direct deposition method of $2 \mathrm{D}$ inks such as graphene, ${ }^{[25,67]} \mathrm{TMDs}^{[119 \mathrm{c}, 141]}$ and BP. ${ }^{[85 c]}$ Spin-coating of LPE 2DMs consists of the deposition of a drop of nanosheet suspension onto a flat substrate with subsequent spinning at high speed (typical velocity in the range of $1000-10000 \mathrm{rpm}^{[142]}$ ), resulting in a thin coating of the substrate with ejection of the excess liquid by centrifugal force. The dispersion may be deposited prior or during substrate rotation. Once the excess material has been removed during the rotation process, the solvent of the remaining dispersion evaporates. Key parameters influencing the thickness of the film include concentration of the materials dispersion, viscosity, rotation speed and the wettability of the substrate. ${ }^{[143]}$

The upside of this technique consists in the ease of process and the accurate control of the thin-film thickness and surface topography. ${ }^{[144]}$ However, the disadvantages is the high rate of ink waste and the high concentration requirement to obtain homogeneous coverage. Spincoating of 2DMs dispersions in high boiling point solvents is challenging due to wetting issues, with only a few 2DM sheets remaining on the surface of the substrate, rendering it an unsuitable technique to form uniform films. Hence, spin-coating is often used to prepare single flakes of a 2DM on a substrate, as exemplified by Yang et al.$^{[85 \mathrm{c}]}$ who fabricated bottom-gate and gold bottom-contact devices by spin-coating of a BP dispersion onto a commercial electrode-patterned device. Field-effect transistors based on thin layered single BP flakes display a high mobility of $252 \mathrm{~cm}^{2} \mathrm{~V}^{-1} \mathrm{~s}^{-1}$ and an $\mathrm{I}_{\mathrm{on}} / \mathrm{I}_{\text {off }}$ ratio exceeding $10^{5}$. To 


\section{WILEY-VCH}

achieve uniform coverage in films produced by spin-coating, a multiple-step approach can be employed. Yang et al. successfully produced a 2-3 nm 2D MoS sheet film used as hole extraction layer in organic solar cells by 3 successive spin-coatings. ${ }^{[141]}$ The film subsequently underwent a 3 min UV-ozone treatment to trigger oxygen incorporation. The devices in which oxygen-incorporated chemically exfoliated $\mathrm{MoS}_{2}$ was used as the hole extraction layer were characterized and a power conversion efficiency of $7.64 \%$ was recorded. This efficiency is comparable to that of the solar cells with standard PEDOT:PSS (7.60\%) as the hole extraction layer.

\subsection{Spray-coating}

Spray-coating is one of the less expensive deposition method, widely used in industrial coating and painting. ${ }^{[145]}$ This technique relies on a continuous spraying of the ink generated in a nozzle and atomised towards the surface of the substrate by application of pressure to a transporting gas (e.g. compressed air), ${ }^{[146]}$ ultrasound automatism (ultrasonic spray deposition) ${ }^{[147]}$ or electrical voltage (electrospray). ${ }^{[148]}$ Usually, the spray trace is small (in the range of 1-25 $\mathrm{mm}^{2}$ ) and well defined, allowing for precise control on the area of deposition. The air pressure level must be adjusted to eliminate ink spattering, which can be caused by excessive air pressure or insufficient atomization. Consequently, spray-coating produces a speckled and uneven painted surface. Other factors to be controlled to obtain a thin-film include the nature of the solvent, ${ }^{[149]}$ the particle size and nozzle geometry ${ }^{[150]}$ and the distance between spray nozzle and substrate. ${ }^{[149]}$ The spray-coating process can easily be integrated in a R2R setup, and using shadow masks, the preparation of patterns can be achieved. ${ }^{[151]}$ However, ink mist resulting from the spray-coating process must be considered since it can potentially lead to contamination of the processing equipment. Furthermore, ink loss and low edge resolution are fundamental issues. 


\section{WILEY-VCH}

Inks based on 2DMs suitable for spray-coating can be produced by UILPE of graphite ${ }^{[152]}$ and TMDs ${ }^{[71,153]}$ in commonly used solvents (e.g. DMF and NMP, and EE of HOPG in the mixture of $\mathrm{H}_{2} \mathrm{SO}_{4}$ and $\mathrm{KOH} .{ }^{[154]}$ Spray-coating is a contact-free technique suitable with roomtemperature processing or large area fabrication. As a result, solutions can be readily deposited onto rigid or flexible substrates, such as $\mathrm{PET}^{[71,154]}$ or TCO (FTO coated glass). ${ }^{[152]}$ In addition, substrates with different shapes can also be processed using spray-coating. Recently, Carey et al. ${ }^{[155]}$ demonstrated spray-coating of graphene ink on the inside of a poly(methyl methacrylate) sphere, enabling transparent capacitive-touch sensor. They used hybrid inks of graphene/poly(3,4-ethylenedioxythiophene): poly(styrenesulfonate) (PEDOT:PSS) stabilized by the $\pi-\pi$ interaction between the graphene sheets and the backbone of the PEDOT and the electrostatic repulsion between the negatively charged PSS, to achieve $156 \mathrm{~nm}$ thick films with a root-mean-square roughness $\left(\mathrm{R}_{\mathrm{RMS}}\right)$ of $48{ }^{[156]} \mathrm{Inks}$ deposited on 3D curved surfaces were used to achieve interactive devices, connected to a microprocessor, allowing for an audio response when touched (Fig. 7).

Lin et al. ${ }^{[157]}$ exploited the ultrasonic spray-coating method to produce optically transparent and electrically conductive films based on graphene and conductive silver and copper nanofilaments. This method relied on the formation of aerosol droplets of a conducting nanofilament dispersion and the formation of aerosol droplets of a second dispersion of graphene. The droplets were sprayed onto a supporting substrate resulting in films exhibiting an optical transparency of $80 \%$ and a sheet resistance below $300 \Omega \mathrm{sq}^{-1}$.

\subsection{Langmuir-Blodgett/ Langmuir-Schaefer}

Langmuir-Blodgett (LB) and Langmuir-Schaefer (LS) are film processing techniques which allow fabrication of thin-films with control over the packing density of nanoparticles. In these methods, a single layer of molecules is first organized on a liquid surface, usually water, 


\section{WILEY-VCH}

before being compacted and finally transferred onto a solid support to form a thin-film. The film can be deposited vertically in the case of LB or horizontally in the case of LS. A wellorganized multilayer film with desired structure and thickness can be achieved by repeating the deposition process. ${ }^{[158]}$ Compared to the previously described deposition techniques, LB is highly controllable and a high-quality film can be produced with good reproducibility and little waste of material. However, film fabrication via LB/LS techniques is a very timeconsuming process, and requires maximal purity of components. ${ }^{[159]}$ Even small contaminations can have substantial effects on the quality of the deposited film, so while LB assembly is routinely used in research laboratories, the technique has not yet become a scalable manufacturing tool for 2DMs.

Hitherto, exfoliated graphene $\mathrm{e}^{[64 \mathrm{~b}, 68,160]}$ and $\mathrm{BP}^{[161]}$ have been organized into LB films. Kim et $a l .{ }^{[160 \mathrm{a}]}$ reported on the formation of LB films from graphene/NMP dispersion. The increase of the lateral size during optimization UILPE process and denser packing of graphene sheets in the LB assembly allowed an improvement of the conductivity of the thin-film up to $10^{4} \mathrm{~S} \mathrm{~m}^{-1}$. The authors fabricated 7-40 $\mathrm{nm}$ films and determined a percolation film thickness of about 10 $\mathrm{nm}$. However, in case of BP, the surface easily gets oxidized in presence of water as well as ambient oxygen. ${ }^{[162]}$ Therefore, Kaur et al. ${ }^{[161]}$ exfoliated BP in NMP by UILPE and used deoxygenated water as sub-phase medium for LB assembly.

\subsection{Dry-transfer}

The dry transfer process is aimed at transferring part or all of a thin-film from one substrate to a designated area of another. Nanosheet-based thin-films, which are formed by filtering the dispersion through a porous membrane can be transferred onto the desired rigid or flexible substrates. Therefore the, vacuum filtration assembly technology is widely used to form membranes of 2DMs produced by LPE. ${ }^{[163]}$ Using a vacuum pump, the solvent passes through 


\section{WILEY-VCH}

the filter and the 2DMs form a membrane on top. The thickness of the films can be adjusted through the filtration volume and the concentration of the nanosheet dispersion. The maximum film area being limited to the area of the filtration membrane.

Surfactants and molecules commonly used to prepare stable 2DMs dispersion can be removed during vacuum filtration after film formation by simply passing additional solvent (typically water) through the film. Vacuum filtration avoids residual surfactant/solvent contamination and spatial nonuniformity, which cannot be eliminated in common coating techniques such as spin-coating or drop-casting. However, when the deposition of 2DMs onto large area substrate is required, alternative techniques such as spray-coating or inkjet printing are preferable.

To perform the transfer, the coated membrane can be simply mechanically pressed on a target substrate. Parvez et al. ${ }^{[64 \mathrm{a}]}$ used the pressure assisted dry transfer technique to produce $50 \mathrm{~nm}$ thick EEG based electrodes on various substrates (e.g. PET, $\mathrm{SiO}_{2}$ ), where van der Waals interactions between the graphene and substrate occurred. Thickness and transmittance of the transferred films were controlled during the vacuum filtration process by fine-tuning of the concentration of the graphene dispersion. Dry transfer was demonstrated to be an effective tool for rigid and flexible organic electronic device coating. Moreover, the pressure assisted dry transfer did not cause contamination, since it avoids dissolution of the filter membrane. ${ }^{[64 a]}$ Recently, Kang et al. ${ }^{[78]}$ demonstrated that the stamp transfer strategy also provides an efficient transfer scheme for solution-processed 2DMs that has been utilized for high-performance single flake BP-based field-effect transistors.

\subsection{Inkjet printing}

Since the late 1970s, inkjet printers capable of reproducing digital images generated by computers have been developed. ${ }^{[164]}$ While inkjet printing has traditionally been used in 


\section{WILEY-VCH}

publishing industry, it has also more recently become a popular method in fabrication of electronic and mechanical devices due to the flexible and cheap nature of this deposition technology involving a limited number of process steps and low material waste. Unlike competing deposition methods such as spin-coating and drop-casting, inkjet printing enables space-confined patterning via material deposition based on a layout designed in software. ${ }^{[165]}$ Hence, the inkjet printing has been widely employed in the fabrication of a wide range of (opto)electronic devices, ${ }^{[58,71,166]}$ is the most widely used printing methods for printed electronics, ${ }^{[167]}$ and among the most promising approach for flexible and wearable electronics. ${ }^{[59-60,61 b, 168]}$ All inkjet technologies are based on the digitally controlled generation and ejection of droplets of liquid inks with typical diameters of 50-80 $\mu \mathrm{m}$ from a print head nozzle onto a desired substrate. ${ }^{[169]}$ The film may subsequently be transferred from one substrate to another by means of a polydimethylsiloxane (PDMS) stamp.

Hitherto, considerable attention has been paid to inkjet printing of inks based on 2DMs. ${ }^{[59 b, 61 a \text {, }}$ ${ }^{71,170]}$ Hersam's group presented notable reports of progress in this field of graphene ink formulation, and reported on the production of graphene/EC-based ink formulations using both UILPE ${ }^{[59 b]}$ and $\mathrm{HSE}^{[171]}$. The authors printed $14 \mathrm{~nm}$ thick graphene ink on $\mathrm{SiO}_{2}{ }^{[59 b]}$ or glass ${ }^{[171]}$ substrates previously treated with hexamethyldisilazane (HDMS) to prevent undesired coffee ring effects of the printed features, achieving conductivities reaching $\approx 2.5 \times 10^{4} \mathrm{~S} \mathrm{~m}^{-1}$ on $190 \mathrm{~nm}$ thick films. ${ }^{[59 b, 171]}$

Majee et al. demonstrated scalable and efficient inkjet printing of graphene flexible transparent conducting films. The printed graphene films exhibited a conductivity of $\sim 4 \times 10^{4}$ $\mathrm{S} \mathrm{m}^{-1}$ and an optical transparency of $86 \%$, complemented by excellent flexibility and air stability ${ }^{[62]}$ Torrisi et al. ${ }^{[61 a]}$ reported an inkjet printed graphene TFTs with carrier mobility up to $\sim 95 \mathrm{~cm}^{2} \mathrm{~V}^{-1} \mathrm{~s}^{-1}$ with $80 \%$ transmittance and $\sim 30 \mathrm{k} \Omega \mathrm{sq}^{-1}$ sheet resistance. Li et al. ${ }^{[82 \mathrm{~b}]}$ selected the inkjet printing method to deposit $\mathrm{MoS}_{2}$ inks. The $\mathrm{MoS}_{2}$ nanosheets (>6 layers, 5- 


\section{WILEY-VCH}

$7 \mathrm{~nm}$ thick) were obtained by employing the solvent exchange and polymer (EC) stabilization techniques. Recently, Li et al. ${ }^{[85 b]}$ demonstrated that BP inks obtained by LPE can be suitable for use in large-area inkjet printing to produce uniform BP thin-films for printable optoelectronic devices and exhibited high average hole mobility of $\sim 60 \mathrm{~cm}^{2} \mathrm{~V}^{-1} \mathrm{~s}^{-1}$. There are several challenges to overcome while using 2DMs dispersions for printing techniques. First and foremost, no common solvents with a rheology compatible with inkjet printing are suitable for LPE. Inkjet printing requires a careful tailoring of the viscosity and surface tension of the ink formulation to achieve stable droplet formation. ${ }^{[172]}$ Furthermore, high-concentration dispersions are required to prevent the need for multiple print passes and to avoid aggregation, which may occur during drying. ${ }^{[58]}$ For good compatibility with printing setups, 2D inks can be prepared by UILPE using different approaches. These include the dispersion of 2DMs directly in solvents like NMP or DMF without binder, ${ }^{[61 a, 170 b]}$ and the use of binders as viscosity modifiers and stabilisers. Commonly selected binders include EC ${ }^{58-60 \text {, }}$ ${ }^{61 b, 173]}$ and ethylene glycol. ${ }^{[61 a, 62,170 a]}$ However, UILPE in high boiling point solvents is unsuitable for printing due to its low viscosity and limited ink concentration. On the other hand, binders are insulators and they reduce the conductivity of the inks. To overcome this problem, thermal annealing is needed to decompose the binders, but high temperatures are unsuitable for heat-sensitive substrates (e.g. paper, plastics). To address this issue, the solvent-exchange method has been developed for the production of dispersions of 2DMs compatible with inkjet printing. ${ }^{[71,166]}$

In addition, EE of 2DMs and subsequent sonication in low-boiling point solvents can also be used for large-area inkjet printing and the fabrication of optoelectronic devices. ${ }^{[85 b]} \mathrm{An}$ important undesirable phenomenon attributed to the ink composition is the ring-shaped deposit pattern. ${ }^{[135 a, 135 b]}$ However this can be minimized by approaches such as increasing the amount of solute, printing at high contact angles, using binary mixtures of solvents or printing 


\section{WILEY-VCH}

on highly hydrophobic substrates. ${ }^{[60,174]}$ Inkjet printing, similarly to spray-coating, is well suited for low-viscosity dispersions. Moreover, the lateral size of the dispersed molecules or nanoparticles should be smaller than the nozzle diameter, to prevent clogging. To minimize clustering of the flakes at the nozzle edge, these should be smaller than $1 / 50$ of the nozzle diameter. ${ }^{[61 \mathrm{a}]}$

\subsection{Roll-to-roll}

Roll-to-roll (R2R) printing techniques offer low-cost production onto large-area substrates and are widely used for applications in the packaging industry. ${ }^{[175]}$ The two most commonly employed R2R processes, gravure and flexographic printing, are both being used for a large variety of end applications. These techniques rely on metal rolls to meter and control the ink deposited on the surface. ${ }^{[176]}$ Gravure printing relies on the surface tension transfer of ink from small engraved cavities in the gravure cylinder to the substrate. Flexographic printing is based on the transfer of ink achieved through direct contact of a soft printing plate cylinder onto which the desired motif stands out as a relief, like on a traditional stamp. Both techniques require mobile, low-viscosity and rapidly drying inks. The typical operating viscosity differs between flexographic printing (i.e., in the 1000-2000 $\mathrm{mPa}$ s range) and gravure printing (100-1000 $\mathrm{mPa}$ s). A low viscosity enables the ink to properly fill the recessed gravure cells in the cylinder before being transferred onto the substrate. A major difference between flexographic and gravure printing is the printing speed, with gravure printing being faster $\left(\approx 1000 \mathrm{~m} \mathrm{~min}^{-1}\right)$ than flexographic printing $\left(\approx 500 \mathrm{~m} \mathrm{~min}^{-1}\right){ }^{[177]}$ Successful gravure and flexographic printing processes require inks to be transferred to the substrate in a controlled and uniform way. The rheological characteristics of the inks, solvents, speed of printing, solvent evaporation rate and the nature of the substrate significantly affect this critical step. ${ }^{[177]}$ 


\section{WILEY-VCH}

Recently, R2R techniques have been used for the printing of 2D inks. ${ }^{[59 a, 178]}$

Gravure printing of LPE materials was first demonstrated by Secor et al. in 2014. ${ }^{[59 a]}$ By adapting graphene dispersions originally developed for inkjet printing, ${ }^{[59 b]}$ the authors produced graphene inks from LPE graphite with the stabilizing polymer EC, which allowed to obtain a stable graphene/terpineol polymeric ink with appropriate viscosity varying in the range $0.2-3 \mathrm{~Pa}$ s. Small lateral size LPE graphene sheets $(\sim 50 \mathrm{~nm} \times 50 \mathrm{~nm}$ with typical thickness of $\sim 2 \mathrm{~nm}$ ) were necessary for high-resolution gravure printing where submicrometer particles are needed. ${ }^{[59 a, 179]}$ In addition, the authors proved that the ink was suitable for high-resolution patterning of graphene on Kapton. In 2014, Baker et al..$^{[178]}$ used a graphene/sodium carboxymethylcellulose (Na-CMC) ink with a minimum viscosity of 20 $\mathrm{mPa}$ for R2R flexographic printing. The ink contained a suitable amount of binder at the required viscosity while maintaining the optical transmission of the printed layer. The ink was printed onto ITO substrates to fabricate counter-electrodes for solar cells.

R2R manufacturing among the most promising method for the industrial production of flexible devices, on the account of the ability to fabricate a large number of printed devices simultaneously at high rate. Moreover, R2R can be easily combined with various printing methods such as spray-coating or inkjet printing, which can effectively reduce the processing cost of the deposition and patterning of 2D films. However, compared to inkjet printing of 2D materials, less work has been done thus far using R2R printing. This is largely due to the high set-up cost and the large quantities of ink (>10 L) required for R2R printing. ${ }^{[177]}$ Furthermore, a successful implementation of $\mathrm{R} 2 \mathrm{R}$ into electronics manufacture would require optimization of current printing processes, as well as evaluation of factors affecting the quality of printed features with respect to their electrical behaviour. 


\section{WILEY-VCH}

In this sub-chapter, we have highlighted the different techniques which have been adapted and exploited for the deposition of $2 \mathrm{D}$ inks onto various substrates, for the production of $2 \mathrm{D}$ materials-based films with thicknesses ranging from a few nm (Langmuir Blodgett) to a few hundreds of nanometers (printing). While many among them seem promising for the production of novel electronic devices, each has displayed serious drawbacks preventing widespread industrial use. Furthermore, in many cases, the 2DMs dispersion itself cannot serve as an ink directly. Therefore, many important technological issues must be overcome until a large-scale commercialization of 2DMs based inks can be witnessed. In particular, ink formulation, stability and viscosity required to each printing process, material lifetime after exposure to moisture, oxygen, process time and print speed, yield, uniformity, cost and process monitoring must still be optimized.

Nevertheless, a high degree of control over film thickness in inkjet printed layers has been demonstrated, and new device integration processes and the development of scalable R2R printing processes have resulted in an ever-growing series of electronic and electronic prototypes over the recent years.

\section{Future perspectives}

Considering the remarkable properties of 2DMs and enormous progress made in the field we are poised to enter a new era of materials science that could have far-reaching impacts on the systems we develop. Nowadays, the focus is gradually shifting from studying fundamental properties of graphene to its use in real applications. As far as the quality of graphene devices continues to improve, more breakthroughs can be expected. The study of 2DMs beyond graphene including hexagonal boron nitride, phosphorenes, TMDs and layered oxides have recently emerged and have been explored over the past years. These ultrathin 2DMs can be 


\section{WILEY-VCH}

prepared by means of a wide range of well-developed synthetic methods, which have their own advantages and limitations. Extensive exploration in the field of ultrathin 2DMs also brings new challenges. The successful introduction of 2DMs in products depends not only on the identification of the right products for new and current applications, but also on the ability to provide any chosen material in large quantities at a reasonable cost. In particular, to exploit the potential of $2 \mathrm{D}$ crystals in printed optoelectronics as well as energy storage and conversion, tons of exfoliated 2D crystals are needed. Consequently, as we discussed in this Review Article, LPE methods are playing more and more a central role due to their scalability and versatility. Much of current 2DMs science is based on exfoliation of layered materials and flake transfer to the substrate of interest, which is useful to some applications such as energy storage, however it is not compatible with large-scale nanodevice production. In particular, precise control over size and thickness during the exfoliation remains challenging. Therefore, post-exfoliation size selection is crucial, simply because different applications will require different nanosheet sizes and thicknesses. Furthermore, the optimization of the LPE in specific solvents (non-hazardous and eco-friendly) will be the subject of future efforts to allow compatibly with both printing processes and safety regulations. On the other hand, new technology routes are still being developed and even defective 2DMs can be used in certain applications, e.g. in composites. The manufacturing of new devices requires the detailed understanding of the properties of 2DMs, which is supported by the electronic properties discussed in this work. Our Review aims at stimulating further work in this direction, which will help to solve one of the most critical bottlenecks in the field of 2DMs application. Tuning electronic properties via LPE methods will certainly attract the attention in the next few years. In particular, inks based on graphene and related 2DMs are being explored for printed and flexible electronic devices that in the near future could be embedded into clothing or other surfaces at home or office or in many products such as low-cost sensors integrated in 


\section{WILEY-VCH}

transparent and flexible surfaces, opening the doors for portable apparatus such as smartwearable devices and point of care tools.

\section{Acknowledgements}

This work was supported by the European Commission through the Graphene Flagship Core 2 project (GA No. 785219), the Polish National Science Centre (Grant no. 2015/18/E/ST5/00188 and Grant no. 2016/23/N/ST5/0006), and grant no. POWR.03.02.0000-I023/17 co-financed by the European Union through the European Social Fund under the Operational Program Knowledge Education Development, the Agence Nationale de la Recherche through the Labex project CSC (ANR-10-LABX-0026 CSC) within the Investissement d'Avenir program (ANR-10-120 IDEX-0002-02), and the International Center for Frontier Research in Chemistry (icFRC).

Received: ((will be filled in by the editorial staff))

Revised: ((will be filled in by the editorial staff)) Published online: ((will be filled in by the editorial staff)) 


\section{References}

[1] A. A. Balandin, S. Ghosh, D. Teweldebrhan, I. Calizo, W. Bao, F. Miao, C. N. Lau, 2008 Ieee Silicon Nanoelectronics Workshop 2008, 161.

[2] R. R. Nair, P. Blake, A. N. Grigorenko, K. S. Novoselov, T. J. Booth, T. Stauber, N. M. Peres, A. K. Geim, Science 2008, 320, 1308.

[3] M. D. Stoller, S. Park, Y. Zhu, J. An, R. S. Ruoff, Nano Lett. 2008, 8, 3498.

[4] C. Lee, X. Wei, J. W. Kysar, J. Hone, Science 2008, 321, 385.

[5] B. Radisavljevic, A. Radenovic, J. Brivio, V. Giacometti, A. Kis, Nat. Nanotechnol. 2011, 6, 147.

[6] Y. Kubota, K. Watanabe, O. Tsuda, T. Taniguchi, Science 2007, 317, 932.

[7] J. Kang, V. K. Sangwan, J. D. Wood, M. C. Hersam, Acc. Chem. Res. 2017, 50, 943.

[8] a) K. S. Novoselov, V. I. Fal'ko, L. Colombo, P. R. Gellert, M. G. Schwab, K. Kim, Nature 2012, 490, 192; b) C. Anichini, W. Czepa, D. Pakulski, A. Aliprandi, A. Ciesielski, P. Samorì, Chem. Soc. Rev. 2018, 47, 4860.

[9] F. Bonaccorso, A. Lombardo, T. Hasan, Z. P. Sun, L. Colombo, A. C. Ferrari, Mater. Today 2012, 15, 564.

[10] a) F. Bonaccorso, Z. Sun, T. Hasan, A. C. Ferrari, Nat. Photonics 2010, 4, 611; b) C. L. Tan, X. H. Cao, X. J. Wu, Q. Y. He, J. Yang, X. Zhang, J. Z. Chen, W. Zhao, S. K. Han, G. H. Nam, M. Sindoro, H. Zhang, Chem. Rev. 2017, 117, 6225; c) Y. Zhang, L. Zhang, C. Zhou, Acc. Chem. Res. 2013, 46, 2329.

[11] a) H. Li, Y. Li, A. Aljarb, Y. Shi, L.-J. Li, Chem. Rev. 2018, 118, 6134; b) H. Tetlow, J. Posthuma de Boer, I. J. Ford, D. D. Vvedensky, J. Coraux, L. Kantorovich, Phys. Rep. 2014, 542, 195.

[12] A. Ciesielski, P. Samorì, Chem. Soc. Rev. 2014, 43, 381. 


\section{WILEY-VCH}

[13] J. N. Israelachvili, Intermolecular and Surface Forces, 3rd Edition, 2011.

[14] V. Nicolosi, M. Chhowalla, M. G. Kanatzidis, M. S. Strano, J. N. Coleman, Science 2013, 340, 1420 .

[15] a) A. Ciesielski, S. Haar, A. Aliprandi, M. El Garah, G. Tregnago, G. F. Cotella, M. El Gemayel, F. Richard, H. Sun, F. Cacialli, F. Bonaccorso, P. Samorì, ACS Nano 2016, 10, 10768; b) A. Ciesielski, P. Samorì, Adv. Mater. 2016, 28, 6030; c) V. Štengl, J. Henych, M. Slušná, P. Ecorchard, Nanoscale Res. Lett. 2014, 9, 167.

[16] a) A. M. Abdelkader, A. J. Cooper, R. A. W. Dryfe, I. A. Kinloch, Nanoscale 2015, 7, 6944; b) N. Liu, P. Kim, J. H. Kim, J. H. Ye, S. Kim, C. J. Lee, ACS Nano 2014, 8, 6902.

[17] a) E. Varrla, C. Backes, K. R. Paton, A. Harvey, Z. Gholamvand, J. McCauley, J. N. Coleman, Chem. Mater. 2015, 27, 1129; b) K. R. Paton, E. Varrla, C. Backes, R. J. Smith, U. Khan, A. O’Neill, C. Boland, M. Lotya, O. M. Istrate, P. King, T. Higgins, S. Barwich, P. May, P. Puczkarski, I. Ahmed, M. Moebius, H. Pettersson, E. Long, J. Coelho, S. E. O’Brien, E. K. McGuire, B. M. Sanchez, G. S. Duesberg, N. McEvoy, T. J. Pennycook, C. Downing, A. Crossley, V. Nicolosi, J. N. Coleman, Nat. Mater. 2014, 13, 624 .

[18] W. Qian, R. Hao, Y. Hou, Y. Tian, C. Shen, H. Gao, X. Liang, Nano Res. 2009, 2, 706.

[19] P. G. Karagiannidis, S. A. Hodge, L. Lombardi, F. Tomarchio, N. Decorde, S. Milana, I. Goykhman, Y. Su, S. V. Mesite, D. N. Johnstone, R. K. Leary, P. A. Midgley, N. M. Pugno, F. Torrisi, A. C. Ferrari, ACS Nano 2017, 11, 2742.

[20] V. León, M. Quintana, M. A. Herrero, J. L. G. Fierro, A. d. 1. Hoz, M. Prato, E. Vázquez, Chem. Commun. 2011, 47, 10936. 


\section{WILEY-VCH}

[21] S. Bertolazzi, M. Gobbi, Y. Zhao, C. Backes, P. Samorì, Chem. Soc. Rev. 2018, 47, 6845

[22] a) M. R. Lukatskaya, O. Mashtalir, C. E. Ren, Y. Dall'Agnese, P. Rozier, P. L.

Taberna, M. Naguib, P. Simon, M. W. Barsoum, Y. Gogotsi, Science 2013, 341, 1502;

b) M. Naguib, M. Kurtoglu, V. Presser, J. Lu, J. Niu, M. Heon, L. Hultman, Y.

Gogotsi, M. W. Barsoum, Adv. Mater. 2011, 23, 4248; c) F. Shahzad, M. Alhabeb, C.

B. Hatter, B. Anasori, S. Man Hong, C. M. Koo, Y. Gogotsi, Science 2016, 353, 1137;

d) M. Ghidiu, M. R. Lukatskaya, M.-Q. Zhao, Y. Gogotsi, M. W. Barsoum, Nature 2014, 516, 78 .

[23] a) A. C. Ferrari, J. C. Meyer, V. Scardaci, C. Casiraghi, M. Lazzeri, F. Mauri, S.

Piscanec, D. Jiang, K. S. Novoselov, S. Roth, A. K. Geim, Phys. Rev. Lett. 2006, 97, 187401; b) Y. Hernandez, V. Nicolosi, M. Lotya, F. M. Blighe, Z. Sun, S. De, I. T.

McGovern, B. Holland, M. Byrne, Y. K. Gun'Ko, J. J. Boland, P. Niraj, G. Duesberg, S. Krishnamurthy, R. Goodhue, J. Hutchison, V. Scardaci, A. C. Ferrari, J. N.

Coleman, Nat. Nanotechnol. 2008, 3, 563; c) J. C. Meyer, A. K. Geim, M. I.

Katsnelson, K. S. Novoselov, T. J. Booth, S. Roth, Nature 2007, 446, 60.

[24] J. H. Ding, H. R. Zhao, Q. L. Wang, H. M. Dou, H. Chen, H. B. Yu, Nanoscale 2017, 9, 16871.

[25] M. Eredia, S. Bertolazzi, T. Leydecker, M. El Garah, I. Janica, G. Melinte, O. Ersen, A. Ciesielski, P. Samorì, J. Phys. Chem. Lett. 2017, 8, 3347.

[26] Y. Wang, C. C. Mayorga-Martinez, X. Chia, Z. Sofer, M. Pumera, Nanoscale 2018, 10,7298 .

[27] J. N. Coleman, M. Lotya, A. O’Neill, S. D. Bergin, P. J. King, U. Khan, K. Young, A. Gaucher, S. De, R. J. Smith, I. V. Shvets, S. K. Arora, G. Stanton, H.-Y. Kim, K. Lee, G. T. Kim, G. S. Duesberg, T. Hallam, J. J. Boland, J. J. Wang, J. F. Donegan, J. C. 


\section{WILEY-VCH}

Grunlan, G. Moriarty, A. Shmeliov, R. J. Nicholls, J. M. Perkins, E. M. Grieveson, K. Theuwissen, D. W. McComb, P. D. Nellist, V. Nicolosi, Science 2011, 331, 568.

[28] L. Chen, G. Zhou, Z. Liu, X. Ma, J. Chen, Z. Zhang, X. Ma, F. Li, H.-M. Cheng, W. Ren, Adv. Mater. 2016, 28, 510.

[29] C. Backes, R. J. Smith, N. McEvoy, N. C. Berner, D. McCloskey, H. C. Nerl, A. O’Neill, P. J. King, T. Higgins, D. Hanlon, N. Scheuschner, J. Maultzsch, L. Houben, G. S. Duesberg, J. F. Donegan, V. Nicolosi, J. N. Coleman, Nat. Commun. 2014, 5, 4576.

[30] C. Backes, B. M. Szydłowska, A. Harvey, S. Yuan, V. Vega-Mayoral, B. R. Davies, P.-1. Zhao, D. Hanlon, E. J. G. Santos, M. I. Katsnelson, W. J. Blau, C. Gadermaier, J. N. Coleman, ACS Nano 2016, 10, 1589.

[31] D. Hanlon, C. Backes, E. Doherty, C. S. Cucinotta, N. C. Berner, C. Boland, K. Lee, A. Harvey, P. Lynch, Z. Gholamvand, S. Zhang, K. Wang, G. Moynihan, A. Pokle, Q. M. Ramasse, N. McEvoy, W. J. Blau, J. Wang, G. Abellan, F. Hauke, A. Hirsch, S. Sanvito, D. D. O’Regan, G. S. Duesberg, V. Nicolosi, J. N. Coleman, Nat. Commun. 2015, 6, 8563 .

[32] A. C. Ferrari, D. M. Basko, Nat. Nanotechnol. 2013, 8, 235.

[33] A. C. Ferrari, J. Robertson, Phys. Reb. B 2000, 61, 14095.

[34] K.-G. Zhou, F. Withers, Y. Cao, S. Hu, G. Yu, C. Casiraghi, ACS Nano 2014, 8, 9914.

[35] F. Tuinstra, J. L. Koenig, J Chem. Phys. 1970, 53, 1126.

[36] a) A. Gupta, G. Chen, P. Joshi, S. Tadigadapa, P. C. Eklund, Nano Lett. 2006, 6, 2667;

b) D. Graf, F. Molitor, K. Ensslin, C. Stampfer, A. Jungen, C. Hierold, L. Wirtz, Nano Lett. 2007, 7, 238.

[37] M. M. Lucchese, F. Stavale, E. H. M. Ferreira, C. Vilani, M. V. O. Moutinho, R. B. Capaz, C. A. Achete, A. Jorio, Carbon 2010, 48, 1592. 


\section{WILEY-VCH}

[38] a) W. Zhao, Z. Ghorannevis, K. K. Amara, J. R. Pang, M. Toh, X. Zhang, C. Kloc, P. H. Tan, G. Eda, Nanoscale 2013, 5, 9677; b) X. Zhang, X.-F. Qiao, W. Shi, J.-B. Wu, D.-S. Jiang, P.-H. Tan, Chem. Soc. Rev. 2015, 44, 2757; c) C. Lee, H. Yan, L. E. Brus, T. F. Heinz, J. Hone, S. Ryu, ACS Nano 2010, 4, 2695; d) X. Zhang, Q.-H. Tan, J.-B. Wu, W. Shi, P.-H. Tan, Nanoscale 2016, 8, 6435.

[39] S. Jiménez Sandoval, D. Yang, R. F. Frindt, J. C. Irwin, Phys. Reb. B 1991, 44, 3955.

[40] A.-L. Phaneuf-L'Heureux, A. Favron, J.-F. Germain, P. Lavoie, P. Desjardins, R. Leonelli, R. Martel, S. Francoeur, Nano Lett. 2016, 16, 7761.

[41] M. Lazzeri, S. Piscanec, F. Mauri, A. C. Ferrari, J. Robertson, Phys. Reb. B 2006, 73, 155426.

[42] a) S. J. R. Tan, I. Abdelwahab, Z. Ding, X. Zhao, T. Yang, G. Z. J. Loke, H. Lin, I. Verzhbitskiy, S. M. Poh, H. Xu, C. T. Nai, W. Zhou, G. Eda, B. Jia, K. P. Loh, J. Am. Chem. Soc. 2017, 139, 2504; b) M. El Garah, S. Bertolazzi, S. Ippolito, M. Eredia, I. Janica, G. Melinte, O. Ersen, G. Marletta, A. Ciesielski, P. Samorì, FlatChem 2018, 9, 33.

[43] J. Kang, J. D. Wood, S. A. Wells, J.-H. Lee, X. Liu, K.-S. Chen, M. C. Hersam, ACS Nano 2015, 9, 3596.

[44] J. D. Wood, S. A. Wells, D. Jariwala, K.-S. Chen, E. Cho, V. K. Sangwan, X. Liu, L. J. Lauhon, T. J. Marks, M. C. Hersam, Nano Lett. 2014, 14, 6964.

[45] a) L. Niu, J. N. Coleman, H. Zhang, H. Shin, M. Chhowalla, Z. Zheng, Small 2016, 12, 272; b) J. N. Coleman, Adv. Funct. Mater. 2009, 19, 3680; c) M. Cai, D. Thorpe, D. H. Adamson, H. C. Schniepp, J. Mater. Chem. 2012, 22, 24992; d) S. Wu, K. S. Hui, K. N. Hui, $A d v . S c i . \mathbf{2 0 1 8}, 5,1700491$. 


\section{WILEY-VCH}

[46] a) C. E. Hamilton, J. R. Lomeda, Z. Sun, J. M. Tour, A. R. Barron, Nano Lett. 2009, 9, 3460; b) G. Cunningham, M. Lotya, C. S. Cucinotta, S. Sanvito, S. D. Bergin, R. Menzel, M. S. P. Shaffer, J. N. Coleman, ACS Nano 2012, 6, 3468.

[47] U. Khan, A. O'Neill, M. Lotya, S. De, J. N. Coleman, Small 2010, 6, 864.

[48] F. Hennrich, R. Krupke, K. Arnold, J. A. Rojas Stütz, S. Lebedkin, T. Koch, T. Schimmel, M. M. Kappes, J. Phys. Chem. B 2007, 111, 1932.

[49] M. V. Bracamonte, G. I. Lacconi, S. E. Urreta, L. E. F. Foa Torres, J. Phys. Chem. C 2014, 118, 15455.

[50] a) J. N. Coleman, Acc. Chem. Res. 2013, 46, 14; b) M. Lotya, Y. Hernandez, P. J. King, R. J. Smith, V. Nicolosi, L. S. Karlsson, F. M. Blighe, S. De, Z. Wang, I. T. McGovern, G. S. Duesberg, J. N. Coleman, J. Am. Chem. Soc. 2009, 131, 3611; c) M. Lotya, P. J. King, U. Khan, S. De, J. N. Coleman, ACS Nano 2010, 4, 3155; d) A. O’Neill, U. Khan, P. N. Nirmalraj, J. Boland, J. N. Coleman, J. Phys. Chem. C 2011, 115, 5422; e) U. Khan, H. Porwal, A. O’Neill, K. Nawaz, P. May, J. N. Coleman, Langmuir 2011, 27, 9077.

[51] F. Bonaccorso, A. Bartolotta, J. N. Coleman, C. Backes, Adv. Mater. 2016, 28, 6136.

[52] a) J. F. Shen, Y. M. He, J. J. Wu, C. T. Gao, K. Keyshar, X. Zhang, Y. C. Yang, M. X. Ye, R. Vajtai, J. Lou, P. M. Ajayan, Nano Lett. 2015, 15, 5449; b) J. Shen, J. Wu, M. Wang, P. Dong, J. Xu, X. Li, X. Zhang, J. Yuan, X. Wang, M. Ye, R. Vajtai, J. Lou, P. M. Ajayan, Small 2016, 12, 2741; c) K. G. Zhou, N. N. Mao, H. X. Wang, Y. Peng, H. L. Zhang, Angew. Chem. 2011, 123, 11031; d) S.-L. Zhang, H. Jung, J.-S. Huh, J.B. Yu, W.-C. Yang, J. Nanosci. Nanotechnol. 2014, 14, 8518; e) M. Yi, Z. Shen, S. Ma, X. Zhang, J. Nanopart. Res. 2012, 14, 1003.

[53] L. Guardia, M. J. Fernández-Merino, J. I. Paredes, P. Solís-Fernández, S. Villar-Rodil, A. Martínez-Alonso, J. M. D. Tascón, Carbon 2011, 49, 1653. 


\section{WILEY-VCH}

[54] a) X. Wang, P. F. Fulvio, G. A. Baker, G. M. Veith, R. R. Unocic, S. M. Mahurin, M. Chi, S. Dai, Chem. Commun. 2010, 46, 4487; b) D. Nuvoli, L. Valentini, V. Alzari, S. Scognamillo, S. B. Bon, M. Piccinini, J. Illescas, A. Mariani, J. Mater. Chem. 2011, $21,3428$.

[55] a) A. Schlierf, H. Yang, E. Gebremedhn, E. Treossi, L. Ortolani, L. Chen, A. Minoia, V. Morandi, P. Samorì, C. Casiraghi, D. Beljonne, V. Palermo, Nanoscale 2013, 5, 4205; b) H. Yang, Y. Hernandez, A. Schlierf, A. Felten, A. Eckmann, S. Johal, P. Louette, J. J. Pireaux, X. Feng, K. Müllen, V. Palermo, C. Casiraghi, Carbon 2013, 53, 357; c) D. Parviz, S. Das, H. S. T. Ahmed, F. Irin, S. Bhattacharia, M. J. Green, ACS Nano 2012, 6, 8857; d) D.-W. Lee, T. Kim, M. Lee, Chem. Commun. 2011, 47, 8259; e) Y. T. Liang, M. C. Hersam, J. Am. Chem. Soc. 2010, 132, 17661; f) A. Ciesielski, S. Haar, M. El Gemayel, H. Yang, J. Clough, G. Melinte, M. Gobbi, E. Orgiu, M. V. Nardi, G. Ligorio, V. Palermo, N. Koch, O. Ersen, C. Casiraghi, P. Samorì, Angew. Chem. Int. Ed. 2014, 53, 10355; g) S. Haar, M. Bruna, J. X. Lian, F. Tomarchio, Y. Olivier, R. Mazzaro, V. Morandi, J. Moran, A. C. Ferrari, D. Beljonne, A. Ciesielski, P. Samorì, J. Phys. Chem. Lett. 2016, 7, 2714; h) S. Haar, A. Ciesielski, J. Clough, H. Yang, R. Mazzaro, F. Richard, S. Conti, N. Merstorf, M. Cecchini, V. Morandi, C. Casiraghi, P. Samorì, Small 2015, 11, 1691.

[56] a) L. Niu, M. Li, X. Tao, Z. Xie, X. Zhou, A. P. A. Raju, R. J. Young, Z. Zheng, Nanoscale 2013, 5, 7202; b) N. Liyong, L. Kan, Z. Hongyu, C. Ying - San, Z. Wenjun, Y. Feng, Z. Zijian, Small 2014, 10, 4651.

[57] P. May, U. Khan, J. M. Hughes, J. N. Coleman, J. Phys. Chem. C 2012, 116, 24390.

[58] J. Li, F. Ye, S. Vaziri, M. Muhammed, M. C. Lemme, M. Östling, Adv. Mater. 2013, 25,3985 . 


\section{WILEY-VCH}

[59] a) E. B. Secor, S. Lim, H. Zhang, C. D. Frisbie, L. F. Francis, M. C. Hersam, $A d v$. Mater. 2014, 26, 4533; b) E. B. Secor, P. L. Prabhumirashi, K. Puntambekar, M. L. Geier, M. C. Hersam, J. Phys. Chem. Lett. 2013, 4, 1347.

[60] W. J. Hyun, E. B. Secor, M. C. Hersam, C. D. Frisbie, L. F. Francis, Adv. Mater. 2015, 27, 109.

[61] a) F. Torrisi, T. Hasan, W. Wu, Z. Sun, A. Lombardo, T. S. Kulmala, G.-W. Hsieh, S. Jung, F. Bonaccorso, P. J. Paul, D. Chu, A. C. Ferrari, ACS Nano 2012, 6, 2992; b) Y. Gao, W. Shi, W. Wang, Y. Leng, Y. Zhao, Ind. Eng. Chem. Res. 2014, 53, 16777; c) C.-L. Lee, C.-H. Chen, C.-W. Chen, Chem. Eng. J. 2013, 230, 296.

[62] S. Majee, M. Song, S.-L. Zhang, Z.-B. Zhang, Carbon 2016, 102, 51.

[63] S. Yang, A. G. Ricciardulli, S. Liu, R. Dong, M. R. Lohe, A. Becker, M. A. Squillaci, P. Samorì, K. Müllen, X. Feng, Angew. Chem. Int. Ed. 2017, 56, 6669.

[64] a) K. Parvez, R. Li, S. R. Puniredd, Y. Hernandez, F. Hinkel, S. Wang, X. Feng, K. Müllen, ACS Nano 2013, 7, 3598; b) K. Parvez, Z.-S. Wu, R. Li, X. Liu, R. Graf, X. Feng, K. Müllen, J. Am. Chem. Soc. 2014, 136, 6083; c) S. Yang, S. Brüller, Z.-S. Wu, Z. Liu, K. Parvez, R. Dong, F. Richard, P. Samorì, X. Feng, K. Müllen, J. Am. Chem. Soc. 2015, 137, 13927; d) H. Wang, C. Wei, K. Zhu, Y. Zhang, C. Gong, J. Guo, J. Zhang, L. Yu, J. Zhang, ACS Appl. Mater. Interfaces 2017, 9, 34456.

[65] a) W. F. Zhao, M. Fang, F. R. Wu, H. Wu, L. W. Wang, G. H. Chen, J. Mater. Chem. 2010, 20, 5817; b) V. León, A. M. Rodriguez, P. Prieto, M. Prato, E. Vázquez, ACS Nano 2014, 8, 563; c) Z. Chen, H. D. Miao, J. Y. Wu, Y. S. Tang, W. Yang, L. Q. Hou, F. Yang, X. J. Tian, L. Q. Zhang, Y. F. Li, Ind. Eng. Chem. Res. 2017, 56, 6939; d) Y. Lv, L. Yu, C. Jiang, S. Chen, Z. Nie, $R S C A d v$. 2014, 4, 13350; e) C. Teng, D. Xie, J. F. Wang, Z. Yang, G. Y. Ren, Y. Zhu, Adv. Funct. Mater. 2017, 27, 1700240. 


\section{WILEY-VCH}

[66] a) Y. Z. Wang, T. Chen, X. F. Gao, H. H. Liu, X. X. Zhang, Mater. Express 2017, 7, 491; b) K. R. Paton, J. Anderson, A. J. Pollard, T. Sainsbury, Mater. Res. Express 2017, 4, 025604 .

[67] J. Zheng, C.-A. Di, Y. Liu, H. Liu, Y. Guo, C. Du, T. Wu, G. Yu, D. Zhu, Chem. Commun. 2010, 46, 5728 .

[68] K. H. Park, B. H. Kim, S. H. Song, J. Kwon, B. S. Kong, K. Kang, S. Jeon, Nano Lett. 2012, 12, 2871.

[69] a) F. S. Al-Hazmi, G. H. Al-Harbi, G. W. Beall, A. A. Al-Ghamdi, A. Y. Obaid, W. E. Mahmoud, Superlattices Microstruct. 2015, 86, 270; b) T. V. Khai, D. S. Kwak, Y. J. Kwon, H. Y. Cho, T. N. Huan, H. Chung, H. Ham, C. Lee, N. V. Dan, N. T. Tung, H. W. Kim, Chem. Eng. J. 2013, 232, 346.

[70] J. N. Coleman, M. Lotya, A. O'Neill, S. D. Bergin, P. J. King, U. Khan, K. Young, A. Gaucher, S. De, R. J. Smith, I. V. Shvets, S. K. Arora, G. Stanton, H. Y. Kim, K. Lee, G. T. Kim, G. S. Duesberg, T. Hallam, J. J. Boland, J. J. Wang, J. F. Donegan, J. C. Grunlan, G. Moriarty, A. Shmeliov, R. J. Nicholls, J. M. Perkins, E. M. Grieveson, K. Theuwissen, D. W. McComb, P. D. Nellist, V. Nicolosi, Science 2011, 331, 568.

[71] A. G. Kelly, T. Hallam, C. Backes, A. Harvey, A. S. Esmaeily, I. Godwin, J. Coelho, V. Nicolosi, J. Lauth, A. Kulkarni, S. Kinge, L. D. A. Siebbeles, G. S. Duesberg, J. N. Coleman, Science 2017, 356, 69.

[72] A. O’Neill, U. Khan, J. N. Coleman, Chem. Mater. 2012, 24, 2414.

[73] R. J. Smith, P. J. King, M. Lotya, C. Wirtz, U. Khan, S. De, A. O'Neill, G. S. Duesberg, J. C. Grunlan, G. Moriarty, J. Chen, J. Wang, A. I. Minett, V. Nicolosi, J. N. Coleman, Adv. Mater. 2011, 23, 3944.

[74] X. Wang, P. Wu, ACS Appl. Mater. Interfaces 2018, 10, 2504. 


\section{WILEY-VCH}

[75] T. Morishita, H. Okamoto, Y. Katagiri, M. Matsushita, K. Fukumori, Chem. Commun. 2015, 51, 12068.

[76] J. R. Brent, N. Savjani, E. A. Lewis, S. J. Haigh, D. J. Lewis, P. O'Brien, Chem. Commun. 2014, 50, 13338.

[77] a) P. Yasaei, B. Kumar, T. Foroozan, C. Wang, M. Asadi, D. Tuschel, J. E. Indacochea, R. F. Klie, A. Salehi-Khojin, Adv. Mater. 2015, 27, 1887; b) C. Hao, F. Wen, J. Xiang, S. Yuan, B. Yang, L. Li, W. Wang, Z. Zeng, L. Wang, Z. Liu, Y. Tian, Adv. Funct. Mater. 2016, 26, 2016.

[78] J. Kang, S. A. Wells, J. D. Wood, J.-H. Lee, X. Liu, C. R. Ryder, J. Zhu, J. R. Guest, C. A. Husko, M. C. Hersam, Proc. Natl. Acad. Sci. 2016, 113, 11688.

[79] A. E. Del Rio Castillo, V. Pellegrini, H. Sun, J. Buha, D. A. Dinh, E. Lago, A. Ansaldo, A. Capasso, L. Manna, F. Bonaccorso, Chem. Mater. 2018, 30, 506.

[80] a) A. C. Ferrari, F. Bonaccorso, V. Fal'ko, K. S. Novoselov, S. Roche, P. Boggild, S. Borini, F. H. L. Koppens, V. Palermo, N. Pugno, J. A. Garrido, R. Sordan, A. Bianco, L. Ballerini, M. Prato, E. Lidorikis, J. Kivioja, C. Marinelli, T. Ryhanen, A. Morpurgo, J. N. Coleman, V. Nicolosi, L. Colombo, A. Fert, M. Garcia-Hernandez, A. Bachtold, G. F. Schneider, F. Guinea, C. Dekker, M. Barbone, Z. Sun, C. Galiotis, A. N. Grigorenko, G. Konstantatos, A. Kis, M. Katsnelson, L. Vandersypen, A. Loiseau, V. Morandi, D. Neumaier, E. Treossi, V. Pellegrini, M. Polini, A. Tredicucci, G. M. Williams, B. Hee Hong, J.-H. Ahn, J. Min Kim, H. Zirath, B. J. van Wees, H. van der Zant, L. Occhipinti, A. Di Matteo, I. A. Kinloch, T. Seyller, E. Quesnel, X. Feng, K. Teo, N. Rupesinghe, P. Hakonen, S. R. T. Neil, Q. Tannock, T. Lofwander, J. Kinaret, Nanoscale 2015, 7, 4598; b) B. Li, A. V. Klekachev, M. Cantoro, C. Huyghebaert, A. Stesmans, I. Asselberghs, S. De Gendt, S. De Feyter, Nanoscale 2013, 5, 9640. 


\section{WILEY-VCH}

[81] T. Leydecker, M. Eredia, F. Liscio, S. Milita, G. Melinte, O. Ersen, M. Sommer, A. Ciesielski, P. Samorì, Carbon 2018, 130, 495.

[82] a) K. Lee, H. Y. Kim, M. Lotya, J. N. Coleman, G. T. Kim, G. S. Duesberg, $A d v$. Mater. 2011, 23, 4178; b) J. Li, M. M. Naiini, S. Vaziri, M. C. Lemme, M. Östling, Adv. Funct. Mater. 2014, 24, 6524.

[83] X. You, N. Liu, C. J. Lee, J. J. Pak, Mater. Lett. 2014, 121, 31.

[84] A. H. Woomer, T. W. Farnsworth, J. Hu, R. A. Wells, C. L. Donley, S. C. Warren, ACS Nano 2015, 9, 8869.

[85] a) M. B. Erande, M. S. Pawar, D. J. Late, ACS Appl. Mater. Interfaces 2016, 8, 11548; b) J. Li, C. Chen, S. Liu, J. Lu, W. P. Goh, H. Fang, Z. Qiu, B. Tian, Z. Chen, C. Yao, W. Liu, H. Yan, Y. Yu, D. Wang, Y. Wang, M. Lin, C. Su, J. Lu, Chem. Mater. 2018, 30, 2742; c) S. Yang, K. Zhang, A. G. Ricciardulli, P. P. Zhang, Z. Q. Liao, M. R. Lohe, E. Zschech, P. W. M. Blom, W. Pisula, K. Müllen, X. L. Feng, Angew. Chem. Int. Ed. 2018, 57, 4677; d) Z. Huang, H. Hou, Y. Zhang, C. Wang, X. Qiu, X. Ji, Adv. Mater. 2017, 29, 1702372.

[86] L. Liu, Z. Shen, M. Yi, X. Zhang, S. Ma, RSC Adv. 2014, 4, 36464.

[87] J. A. Gantt, E. P. Gatzke, Powder Technol. 2005, 156, 195.

[88] A. T. Utomo, M. Baker, A. W. Pacek, Chem. Eng. Res. Des. 2008, 86, 1397.

[89] A. Zhamu, B. Z. Jang, J. Shi US Patent US8580432B2, 2013.

[90] a) C. T. J. Low, F. C. Walsh, M. H. Chakrabarti, M. A. Hashim, M. A. Hussain, Carbon 2013, 54, 1; b) Z. Y. Xia, S. Pezzini, E. Treossi, G. Giambastiani, F. Corticelli, V. Morandi, A. Zanelli, V. Bellani, V. Palermo, Adv. Funct. Mater. 2013, 23,4684 .

[91] N. Liu, F. Luo, H. Wu, Y. Liu, C. Zhang, J. Chen, Adv. Funct. Mater. 2008, 18, 1518. 


\section{WILEY-VCH}

[92] a) C.-H. Chen, S.-W. Yang, M.-C. Chuang, W.-Y. Woon, C.-Y. Su, Nanoscale 2015, 7, 15362; b) C.-Y. Su, A.-Y. Lu, Y. Xu, F.-R. Chen, A. N. Khlobystov, L.-J. Li, ACS Nano 2011, 5, 2332.

[93] J. Wang, K. K. Manga, Q. Bao, K. P. Loh, J. Am. Chem. Soc. 2011, 133, 8888.

[94] A. M. Abdelkader, I. A. Kinloch, R. A. W. Dryfe, ACS Appl. Mater. Interfaces 2014, $6,1632$.

[95] A. J. Cooper, N. R. Wilson, I. A. Kinloch, R. A. W. Dryfe, Carbon 2014, 66, 340.

[96] Z. Y. Xia, G. Giambastiani, C. Christodoulou, M. V. Nardi, N. Koch, E. Treossi, V. Bellani, S. Pezzini, F. Corticelli, V. Morandi, A. Zanelli, V. Palermo, ChemPlusChem 2014, 79, 439 .

[97] J. M. Munuera, J. I. Paredes, S. Villar-Rodil, M. Ayán-Varela, A. Martínez-Alonso, J. M. D. Tascón, Nanoscale 2016, 8, 2982.

[98] J. M. Munuera, J. I. Paredes, S. Villar-Rodil, M. Ayán-Varela, A. Pagán, S. D. AznarCervantes, J. L. Cenis, A. Martínez-Alonso, J. M. D. Tascón, Carbon 2015, 94, 729.

[99] M. Sevilla, G. A. Ferrero, A. B. Fuertes, Chem. Eur. J. 2016, 22, 17351.

[100] J. Liu, C. K. Poh, D. Zhan, L. Lai, S. H. Lim, L. Wang, X. Liu, N. Gopal Sahoo, C. Li, Z. Shen, J. Lin, Nano Energy 2013, 2, 377.

[101] P. K. M. K, S. Shanthini, C. Srivastava, RSC Adv. 2015, 5, 53865.

[102] A. Ambrosi, M. Pumera, Chem. Eur. J. 2016, 22, 153.

[103] D. Voiry, J. Yang, J. Kupferberg, R. Fullon, C. Lee, H. Y. Jeong, H. S. Shin, M. Chhowalla, Science 2016, 353, 1413.

[104] J. Liu, M. Notarianni, G. Will, V. T. Tiong, H. Wang, N. Motta, Langmuir 2013, 29, 13307.

[105] A. C. Ferrari, J. C. Meyer, V. Scardaci, C. Casiraghi, M. Lazzeri, F. Mauri, S. Piscanec, D. Jiang, K. S. Novoselov, S. Roth, A. K. Geim, Phys. Rev. Lett. 2006, 97. 


\section{WILEY-VCH}

[106] J. Lu, J.-X. Yang, J. Wang, A. Lim, S. Wang, K. P. Loh, ACS Nano 2009, 3, 2367.

[107] A. Samuni, S. Goldstein, A. Russo, J. B. Mitchell, M. C. Krishna, P. Neta, J. Am. Chem. Soc. 2002, 124, 8719.

[108] a) A. Ambrosi, Z. Sofer, M. Pumera, Angew. Chem. Int. Ed. 2017, 56, 10443; b) J. Zheng, X. Tang, Z. Yang, Z. Liang, Y. Chen, K. Wang, Y. Song, Y. Zhang, J. Ji, Y. Liu, D. Fan, H. Zhang, Adv. Opt. Mater. 2017, 5, 1700026.

[109] A. Favron, E. Gaufrès, F. Fossard, A.-L. Phaneuf-L'Heureux, N. Y. W. Tang, P. L. Lévesque, A. Loiseau, R. Leonelli, S. Francoeur, R. Martel, Nat. Mater. 2015, 14, 826.

[110] a) G.-L. Xu, Z. Chen, G.-M. Zhong, Y. Liu, Y. Yang, T. Ma, Y. Ren, X. Zuo, X.-H. Wu, X. Zhang, K. Amine, Nano Lett. 2016, 16, 3955; b) M. Dahbi, N. Yabuuchi, M. Fukunishi, K. Kubota, K. Chihara, K. Tokiwa, X.-f. Yu, H. Ushiyama, K. Yamashita, J.-Y. Son, Y.-T. Cui, H. Oji, S. Komaba, Chem. Mater. 2016, 28, 1625.

[111] M. Zhou, J. Tang, Q. Cheng, G. Xu, P. Cui, L.-C. Qin, Chem. Phys. Lett. 2013, 572, 61.

[112] A. Ejigu, B. Miller, I. A. Kinloch, R. A. W. Dryfe, Carbon 2018, 128, 257.

[113] H. Xiao, M. Zhao, J. Zhang, X. Ma, J. Zhang, T. Hu, T. Tang, J. Jia, H. Wu, Electrochem. Commun. 2018, 89, 10.

[114] Y. Zhao, H. Wang, H. Huang, Q. Xiao, Y. Xu, Z. Guo, H. Xie, J. Shao, Z. Sun, W. Han, X.-F. Yu, P. Li, P. K. Chu, Angew. Chem. Int. Ed. 2016, 55, 5003.

[115] O. R. Luca, J. L. Gustafson, S. M. Maddox, A. Q. Fenwick, D. C. Smith, Org. Chem. Front. 2015, 2, 823.

[116] Y. L. Zhong, T. M. Swager, J. Am. Chem. Soc. 2012, 134, 17896.

[117] a) C. Damm, T. J. Nacken, W. Peukert, Carbon 2015, 81, 284; b) C. Knieke, A. Berger, M. Voigt, R. N. K. Taylor, J. Röhrl, W. Peukert, Carbon 2010, 48, 3196; c) 


\section{WILEY-VCH}

W. Zhao, F. Wu, H. Wu, G. Chen, J. Nanomater. 2010, 2010, 1; d) I. Y. Jeon, H. J. Choi, S. M. Jung, J. M. Seo, M. J. Kim, L. M. Dai, J. B. Baek, J. Am. Chem. Soc. 2013, 135, 1386; e) I.-Y. Jeon, Y.-R. Shin, G.-J. Sohn, H.-J. Choi, S.-Y. Bae, J. Mahmood, S.-M. Jung, J.-M. Seo, M.-J. Kim, D. Wook Chang, L. Dai, J.-B. Baek, Proc. Natl. Acad. Sci. 2012, 109, 5588; f) M. Mao, S. Z. Chen, P. He, H. L. Zhang, H. T. Liu, J. Mater. Chem. A 2014, 2, 4132.

[118] M. Buzaglo, I. P. Bar, M. Varenik, L. Shunak, S. Pevzner, O. Regev, Adv. Mater. 2017, 29, 1603528.

[119] a) W. Lei, V. N. Mochalin, D. Liu, S. Qin, Y. Gogotsi, Y. Chen, Nat. Commun. 2015, 6, 8849; b) Y. Yao, Z. Lin, Z. Li, X. Song, K.-S. Moon, C.-P. Wong, J. Mater. Chem. 2012, 22; c) M. A. Ibrahem, T.-w. Lan, J. K. Huang, Y.-Y. Chen, K.-H. Wei, L.-J. Li, C. W. Chu, $R S C A d v$. 2013, 3, 13193; d) G. Liu, N. Komatsu, ChemNanoMat 2016, 2, 500; e) L. H. Li, Y. Chen, G. Behan, H. Z. Zhang, M. Petravic, A. M. Glushenkov, J. Mater. Chem. 2011, 21, 11862; f) D. Lee, B. Lee, K. H. Park, H. J. Ryu, S. Jeon, S. H. Hong, Nano Lett. 2015, 15, 1238.

[120] Y. G. Yao, Z. Y. Lin, Z. Li, X. J. Song, K. S. Moon, C. P. Wong, J. Mater. Chem. 2012, 22, 13494.

[121] S. Schultz, G. Wagner, K. Urban, J. Ulrich, Chem. Eng. Technol. 2004, 27, 361.

[122] Z. Tang, J. Zhuang, X. Wang, Langmuir 2010, 26, 9045.

[123] D. K. Dang, E. J. Kim, Nanoscale Res. Lett. 2015, 10, 6.

[124] a) J. D. Carey, S. R. P. Silva, Phys. Reb. B 2004, 70, 235417; b) C. Mattevi, G. Eda, S. Agnoli, S. Miller, K. A. Mkhoyan, O. Celik, D. Mastrogiovanni, G. Granozzi, E. Garfunkel, M. Chhowalla, Adv. Funct. Mater. 2009, 19, 2577.

[125] J. Huang, X. Deng, H. Wan, F. Chen, Y. Lin, X. Xu, R. Ma, T. Sasaki, ACS Sustain. Chem. Eng. 2018, 6, 5227. 


\section{WILEY-VCH}

[126] Z. Yan, X. He, L. She, J. Sun, R. Jiang, H. Xu, F. Shi, Z. Lei, Z.-H. Liu, J. Math. Chem. 2018, 4, 129.

[127] A. E. Del Rio Castillo, V. Pellegrini, A. Ansaldo, F. Ricciardella, H. Sun, L. Marasco, J. Buha, Z. Dang, L. Gagliani, E. Lago, N. Curreli, S. Gentiluomo, F. Palazon, M. Prato, R. Oropesa-Nuñez, P. S. Toth, E. Mantero, M. Crugliano, A. Gamucci, A. Tomadin, M. Polini, F. Bonaccorso, Mater. Horizons 2018, 5, 890.

[128] A. Kamyshny, S. Magdassi, Small 2014, 10, 3515.

[129] M. Chhowalla, D. Jena, H. Zhang, Nature Reviews Materials 2016, 1, 16052.

[130] S. Sutar, I. Asselberghs, D. H. C. Lin, A. V. Thean, I. Radu, IEEE Trans. Electron Devices 2017, 64, 2970.

[131] a) K. S. Novoselov, A. K. Geim, S. V. Morozov, D. Jiang, Y. Zhang, S. V. Dubonos, I. V. Grigorieva, A. A. Firsov, Science 2004, 306, 666; b) A. K. Geim, K. S. Novoselov, Nat. Mater. 2007, 6, 183.

[132] C. S. Boland, U. Khan, G. Ryan, S. Barwich, R. Charifou, A. Harvey, C. Backes, Z. Li, M. S. Ferreira, M. E. Mobius, R. J. Young, J. N. Coleman, Science 2016, 354, 1257.

[133] F. Bensebaa, Nanoparticle Technologies: From Lab to Market, Elsevier Science, 2012.

[134] A. F. Routh, Rep. Prog. Phys. 2013, 76, 046603.

[135] a) D. Soltman, V. Subramanian, Langmuir 2008, 24, 2224; b) H. Hu, R. G. Larson, J. Phys. Chem. B 2006, 110, 7090; c) R. D. Deegan, O. Bakajin, T. F. Dupont, G. Huber, S. R. Nagel, T. A. Witten, Nature 1997, 389, 827; d) P. J. Yunker, T. Still, M. A. Lohr, A. G. Yodh, Nature 2011, 476, 308.

[136] S. Cinti, F. Arduini, Biosens. Bioelectron. 2017, 89, 107. 


\section{WILEY-VCH}

[137] a) U. Khan, P. May, A. O’Neill, J. N. Coleman, Carbon 2010, 48, 4035; b) S. Haar, M. El Gemayel, Y. Shin, G. Melinte, M. A. Squillaci, O. Ersen, C. Casiraghi, A. Ciesielski, P. Samorì, Sci. Rep. 2015, 5, 16684; c) N.-W. Pu, C.-A. Wang, Y.-M. Liu, Y. Sung, D.-S. Wang, M.-D. Ger, J. Taiwan Inst. Chem. E. 2012, 43, 140; d) Y. Zhang, M. Edwards, M. K. Samani, N. Logothetis, L. Ye, Y. Fu, K. Jeppson, J. Liu, Carbon 2016, 106, 195; e) J. Zhang, L. Xu, B. Zhou, Y. Zhu, X. Jiang, J. Colloid Interface Sci. 2018, 513, 279.

[138] A. Gupta, V. Arunachalam, S. Vasudevan, J. Phys. Chem. Lett. 2016, 7, 4884.

[139] M. Eslamian, F. Zabihi, Nanoscale Res. Lett. 2015, 10, 462.

[140] F. Soltani-Kordshuli, M. Eslamian, Exp. Therm Fluid Sci. 2017, 89, 238.

[141] X. Yang, W. Fu, W. Liu, J. Hong, Y. Cai, C. Jin, M. Xu, H. Wang, D. Yang, H. Chen, J. Mater. Chem. A 2014, 2, 7727.

[142] D. Grosso, C. Boissière, M. Faustini, The Sol-Gel Handbook, 3 Volume Set: Synthesis, Characterization, and Applications 2015, 2.

[143] K. Norrman, A. Ghanbari-Siahkali, N. B. Larsen, Annu. Rep. Sect. C: Phys. Chem. 2005, 101, 174.

[144] B. T. Chen, Polym. Eng. Sci. 1983, 23, 399.

[145] a) R. A. Ryntz, P. V. Yaneff, Coatings of polymers and plastics, CRC Press, 2003; b) F. Gärtner, T. Stoltenhoff, T. Schmidt, H. Kreye, J. Therm. Spray Technol. 2006, 15, 223.

[146] C. Girotto, B. P. Rand, J. Genoe, P. Heremans, Sol. Energy Mater. Sol. Cells 2009, 93, 454.

[147] K. X. Steirer, M. O. Reese, B. L. Rupert, N. Kopidakis, D. C. Olson, R. T. Collins, D. S. Ginley, Sol. Energy Mater. Sol. Cells 2009, 93, 447. 


\section{WILEY-VCH}

[148] a) G. Taylor, Proc. R. Soc. London, Ser. A 1964, 280, 383; b) O. V. Salata, Curr. Nanosci. 2005, 1, 25.

[149] J. W. Owen, N. A. Azarova, M. A. Loth, M. Paradinas, M. Coll, C. Ocal, J. E. Anthony, O. D. Jurchescu, J. Nanotechnol. 2011, 2011.

[150] H. Assadi, T. Schmidt, H. Richter, J.-O. Kliemann, K. Binder, F. Gärtner, T. Klassen, H. Kreye, J. Therm. Spray Technol. 2011, 20, 1161.

[151] S. S. Keller, F. G. Bosco, A. Boisen, Microelectron. Eng. 2013, 110, 427.

[152] S. Casaluci, M. Gemmi, V. Pellegrini, A. Di Carlo, F. Bonaccorso, Nanoscale 2016, 8, 5368.

[153] L. Cao, S. Yang, W. Gao, Z. Liu, Y. Gong, L. Ma, G. Shi, S. Lei, Y. Zhang, S. Zhang, R. Vajtai, P. M. Ajayan, Small 2013, 9, 2905.

[154] C.-M. Gee, C.-C. Tseng, F.-Y. Wu, H.-P. Chang, L.-J. Li, Y.-P. Hsieh, C.-T. Lin, J.-C. Chen, Displays 2013, 34, 315.

[155] T. Carey, C. Jones, F. Le Moal, D. Deganello, F. Torrisi, ACS Appl. Mater. Interfaces 2018, 10, 19948.

[156] K. Jo, T. Lee, H. J. Choi, J. H. Park, D. J. Lee, D. W. Lee, B.-S. Kim, Langmuir 2011, $27,2014$.

[157] Y.-J. Lin, A. Zhamu, B. Z. Jang, S. Y. Lee, J. C. Lin Patent WO2014159656A1, 2014.

[158] L. M. Toma, R. Y. N. Gengler, E. B. Prinsen, D. Gournis, P. Rudolf, PCCP 2010, 12, 12188.

[159] a) Q. Cao, S. J. Han, G. S. Tulevski, Y. Zhu, D. D. Lu, W. Haensch, Nat. Nanotechnol. 2013, 8, 180; b) L. O. S. Bulhoes, Y. S. Obeng, A. J. Bard, Chem. Mater. 1993, 5, 110.

[160] a) H. Kim, C. Mattevi, H. J. Kim, A. Mittal, K. A. Mkhoyan, R. E. Riman, M. Chhowalla, Nanoscale 2013, 5, 12365; b) T. Tomašević-Ilić, J. Pešić, I. Milošević, J. 


\section{WILEY-VCH}

Vujin, A. Matković, M. Spasenović, R. Gajić, Opt. Quant. Electron. 2016, 48, 319; c)

T. Wang, M. D. J. Quinn, Shannon M. Notley, RSC Adv. 2017, 7, 3222.

[161] H. Kaur, S. Yadav, A. K. Srivastava, N. Singh, J. J. Schneider, O. P. Sinha, V. V. Agrawal, R. Srivastava, Sci. Rep. 2016, 6, 34095.

[162] G. Wang, R. Pandey, S. P. Karna, Wiley Interdisciplinary Reviews: Computational Molecular Science 2017, 7, e1280.

[163] S. De, P. J. King, M. Lotya, A. O'Neill, E. M. Doherty, Y. Hernandez, G. S. Duesberg, J. N. Coleman, Small 2010, 6, 458.

[164] a) I. L. Wieselman, E. Tomash, Ann Hist Comput 1991, 13, 63; b) I. L. Wieselman, E. Tomash, Ann Hist Comput 1991, 13, 203.

[165] A. Salim, S. Lim, Sensors 2017, 17, 2593.

[166] J. Li, M. C. Lemme, M. Östling, ChemPhysChem 2014, 15, 3427.

[167] R. Parashkov, E. Becker, T. Riedl, H. Johannes, W. Kowalsky, Proc. IEEE 2005, 93, 1321.

[168] M. Gao, L. Li, Y. Song, J. Mater. Chem. C 2017, 5, 2971.

[169] G. Cummins, M. P. Y. Desmulliez, Circuit World 2012, 38, 193.

[170] a) Y. Yao, L. Tolentino, Z. Yang, X. Song, W. Zhang, Y. Chen, C.-p. Wong, Adv. Funct. Mater. 2013, 23, 3577; b) D. J. Finn, M. Lotya, G. Cunningham, R. J. Smith, D. McCloskey, J. F. Donegan, J. N. Coleman, J. Mater. Chem. C 2014, 2, 925.

[171] E. B. Secor, B. Y. Ahn, T. Z. Gao, J. A. Lewis, M. C. Hersam, Adv. Mater. 2015, 27, 6683.

[172] L. Dybowska-Sarapuk, K. Kielbasinski, A. Arazna, K. Futera, A. Skalski, D. Janczak, M. Sloma, M. Jakubowska, Nanomaterials-Basel 2018, 8.

[173] S. K. Del, R. Bornemann, A. Bablich, H. Schäfer-Eberwein, J. Li, T. Kowald, M. Östling, P. H. Bolívar, M. Lemme, C. , 2D Mater. 2015, 2, 011003. 


\section{WILEY-VCH}

[174] J. Park, J. Moon, Langmuir 2006, 22, 3506.

[175] M. Jung, J. Kim, H. Koo, W. Lee, V. Subramanian, G. Cho, J. Nanosci. Nanotechnol. 2014, 14, 1303.

[176] K. Suganuma, Introduction to printed electronics, Springer Science \& Business Media, 2014.

[177] L. W. T. Ng, G. Hu, R. C. T. Howe, X. Zhu, Z. Yang, C. Jones, T. Hasan, Printing of Graphene and Related 2D Materials, Springer International Publishing, 2019.

[178] J. Baker, D. Deganello, D. T. Gethin, T. M. Watson, Mater. Res. Innovations 2014, 18,86 .

[179] M. Lahti, S. Leppävuori, V. Lantto, Appl. Surf. Sci. 1999, 142, 367. 


\section{WILEY-VCH}

Ultrasound induced liquid-phase exfoliation (UILPE)

a)

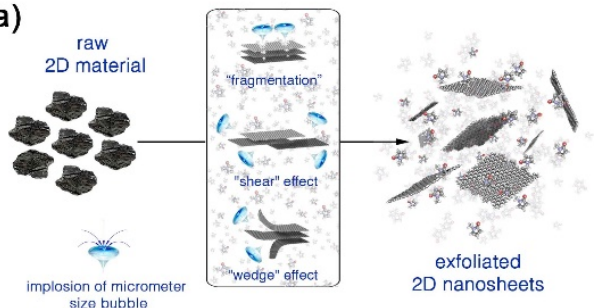

High-shear mixing exfoliation (HSE)

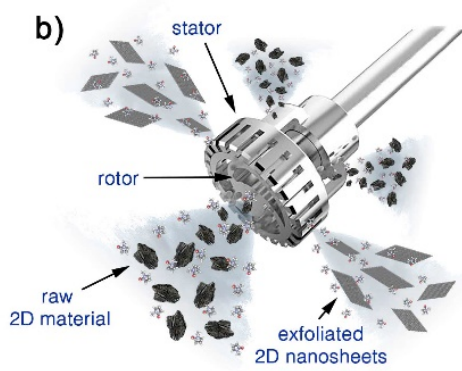

d)

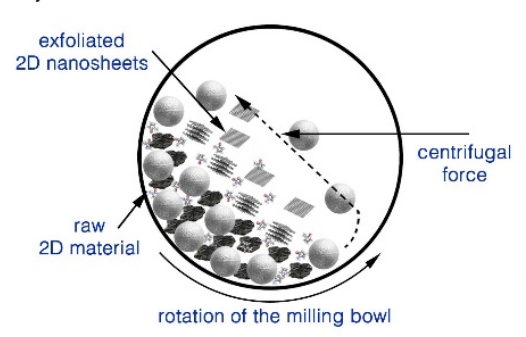

e) Microfluidization

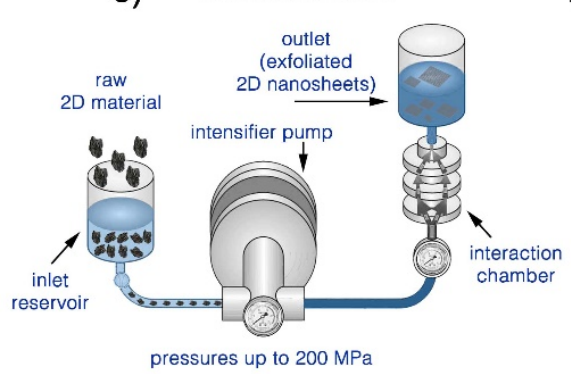

Electrochemical exfoliation (EE)*

c)

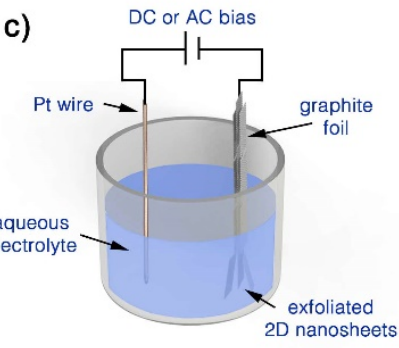

Solvotermal-assisted

f)

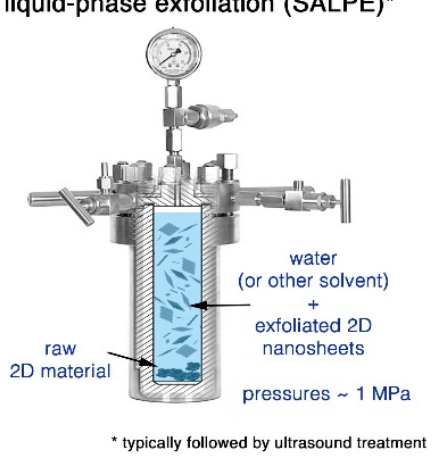

Figure 1. Schematic representation of various liquid phase exfoliation (LPE) based methods such as a) ultrasound induced LPE (UILPE), b) high-shear mixing exfoliation (HSE), c) electrochemical exfoliation (EE), d) ball milling, e) microfluidization and f) solvothermalassisted LPE (SALPE). 


\section{WILEY-VCH}

Graphene

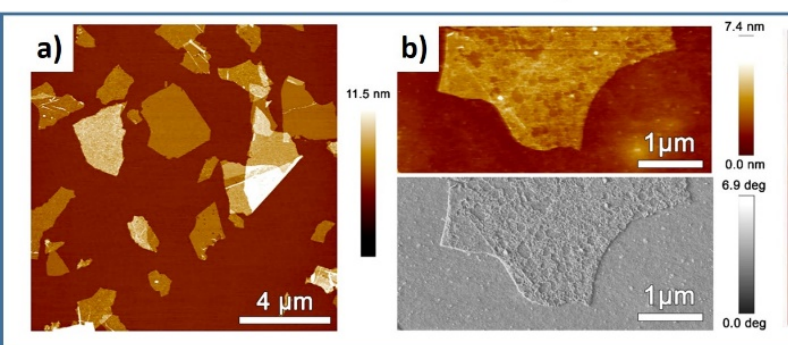

TMDs

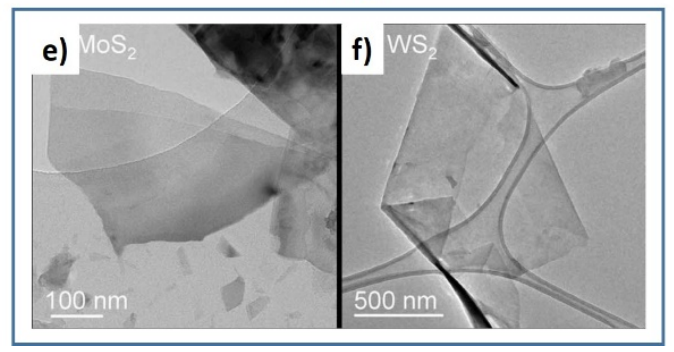

h-BN

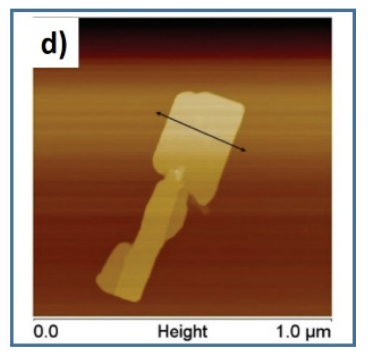

Black Phosphorus

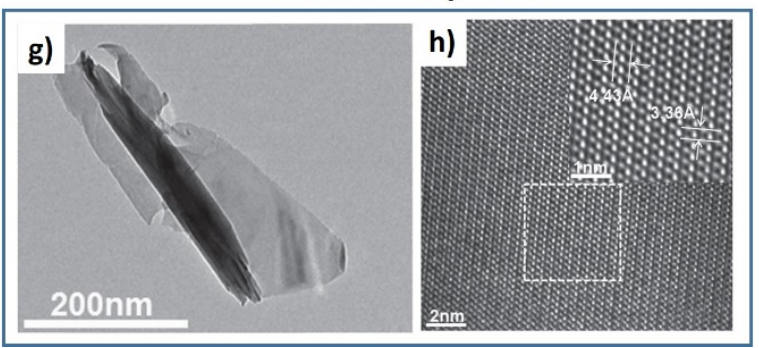

Figure 2. a) AFM image of graphene flakes produced by electrochemical exfoliation (EE) of graphite, b) AFM topographic and phase-contrast images showing structural defects on a representative SL graphene flake. Reproduced with permission. ${ }^{[25]}$ Copyright 2017, American Chemical Society; c) AFM images represent SL and FL graphene. Reprinted with permission. ${ }^{[24]}$ Copyright 2017, Royal Society of Chemistry; d) AFM images of EE h-BN nanosheets. Reprinted with permission. ${ }^{[26]}$ Copyright 2018, Royal Society of Chemistry; Low resolution TEM images of flakes of e) $\mathrm{MoS}_{2}$ and f) $\mathrm{WS}_{2}$. Reproduced with permission. ${ }^{[27]}$ Copyright 2011, American Association for the Advancement of Science; g) TEM image of BP nanosheets, h) High resolution TEM image of a thin BP nanosheet without impurities and defects. Reprinted with permission. ${ }^{[28]}$ Copyright 2015, Wiley-VCH.
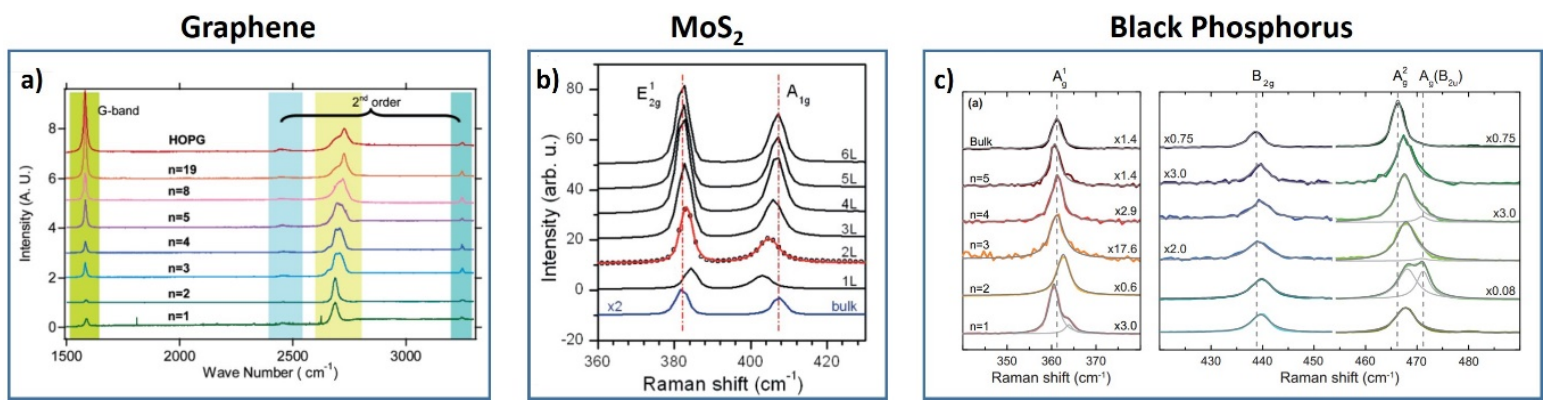

Figure 3. a) Evolution of Raman spectra with the number of graphene layers. Reproduced with permission. ${ }^{[36 a]}$ Copyright 2006, American Chemical Society; b) Raman spectra of bulk $\mathrm{MoS}_{2}$ and $\mathrm{MoS}_{2}$ flakes at different $\mathrm{N}_{\mathrm{L}}$ values from 1 to 5. Reproduced with permission. ${ }^{[38 \mathrm{c}]}$ Copyright 2010, American Chemical Society; c) Raman spectra of bulk BP and separate flakes. Reproduced with permission. ${ }^{[40]}$ Copyright 2016, American Chemical Society. 
Graphene

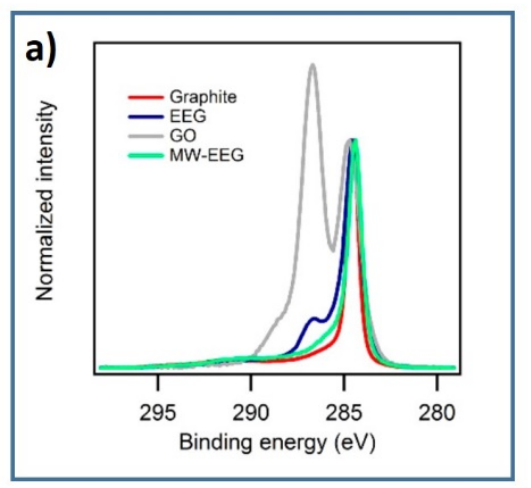

$\mathrm{MoS}_{2}$

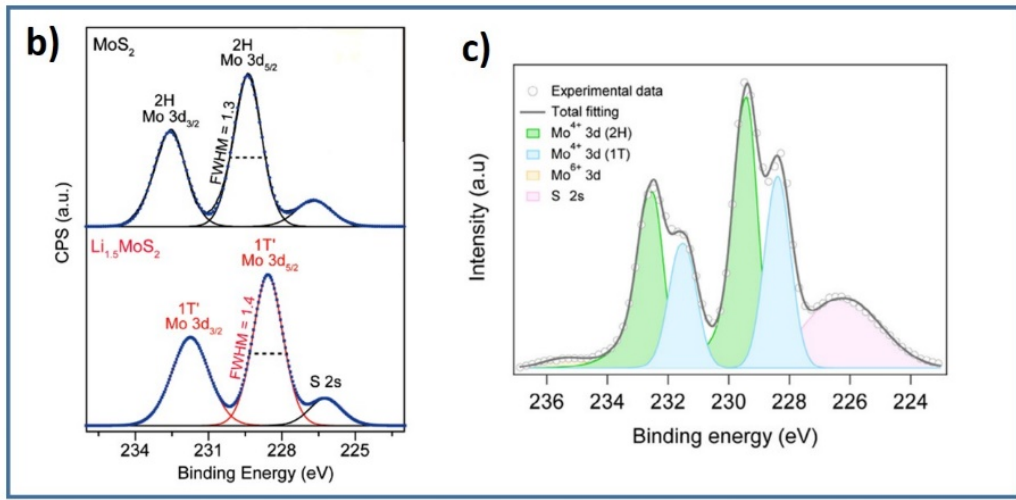

Black Phosphorus

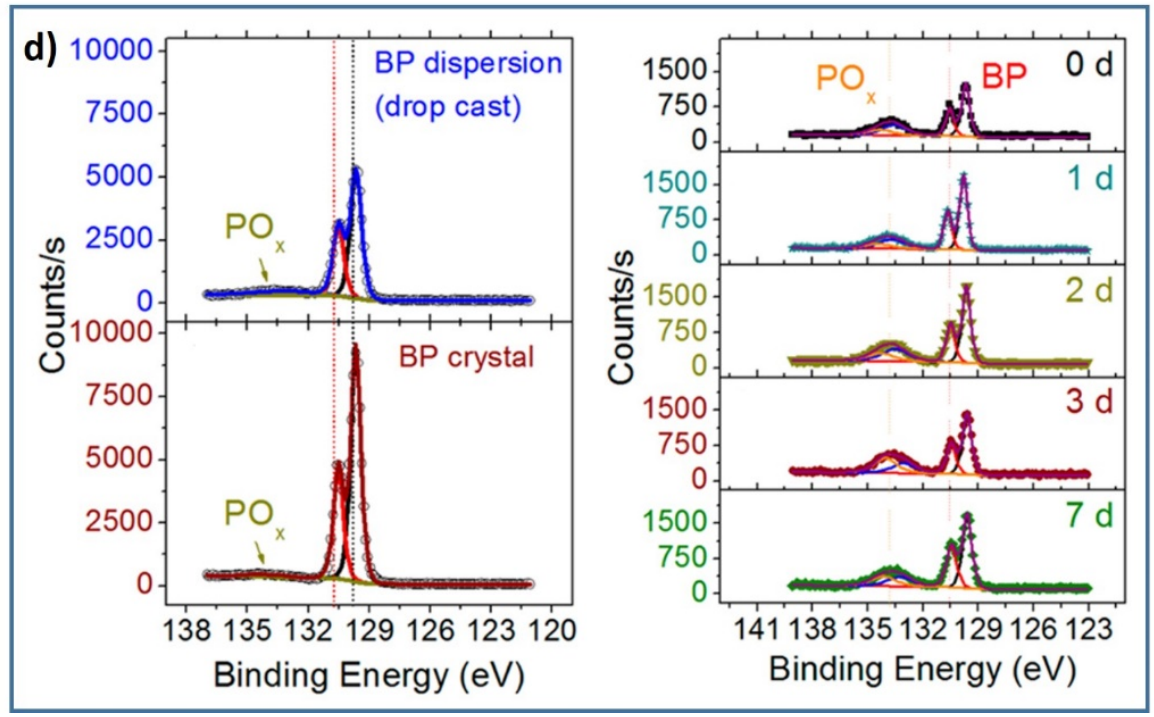

Figure 4. a) XPS characterization (overlapped high resolution carbon spectra) of electrochemically exfoliated graphene (EEG) in comparison with pristine graphite, graphene oxide and EEG after MW irradiation (MW-EEG). Reproduced with permission. ${ }^{[25]}$ Copyright 2017, American Chemical Society; b) XPS spectra showing Mo 3d core levels of pristine 2H$\mathrm{MoS}_{2}$ (top) and fully converted $1 \mathrm{~T}-\mathrm{Li}_{1.5} \mathrm{MoS}_{2}$ (bottom). Reproduced with permission. ${ }^{\text {[42a] }}$ Copyright 2017, American Chemical Society. c) High-resolution XPS spectra of the Mo 3d regions acquired from $\mathrm{MoS}_{2}$ nanosheets prepared via LPE, represent $2 \mathrm{H}$ and $1 \mathrm{~T}$ phases of $\mathrm{MoS}_{2}$. Reproduced with permission. ${ }^{[42 b]}$ Copyright 2018, Elsevier; d) P 2p core-level XPS for bulk BP and exfoliated BP (left); XPS of drop-casted BP dispersions after 0, 1, 2, 3 and 7 days in ambient conditions (right). Reproduced with permission. ${ }^{[43]}$ Copyright 2015 , American Chemical Society. 


\section{WILEY-VCH}

a)

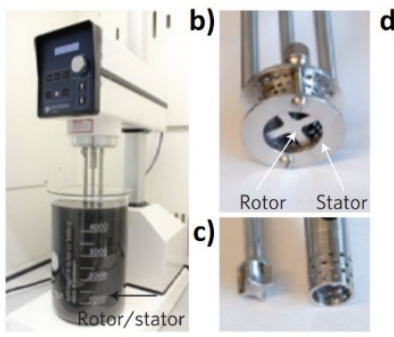

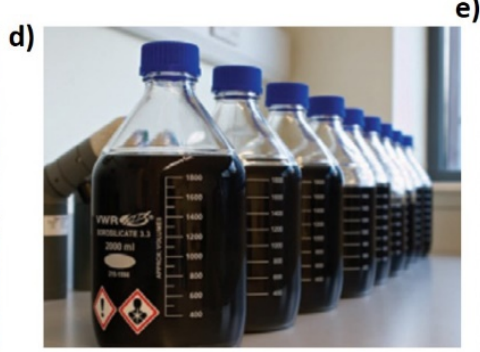
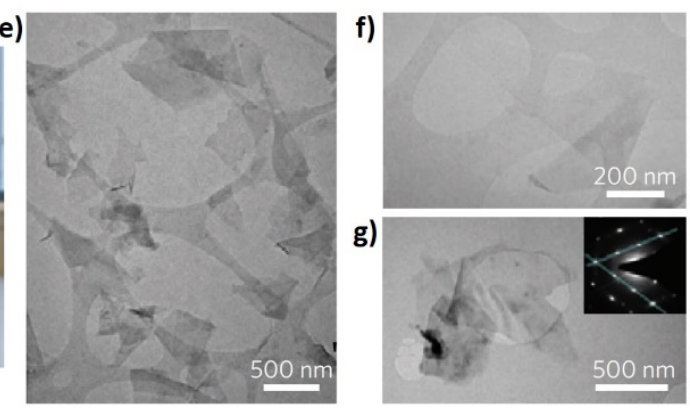

Figure 5. a) High-shear mixer with mixing head in a beaker of graphene dispersion, b, c) Close-up view of mixing heads, d) Graphene-NMP dispersions produced by HSE, e) TEM image of SL graphene nanosheets, $f, g$ ) TEM images of individual nanosheets. Reproduced with permission. ${ }^{[17 b]}$ Copyright 2014, Macmillan Publishers.

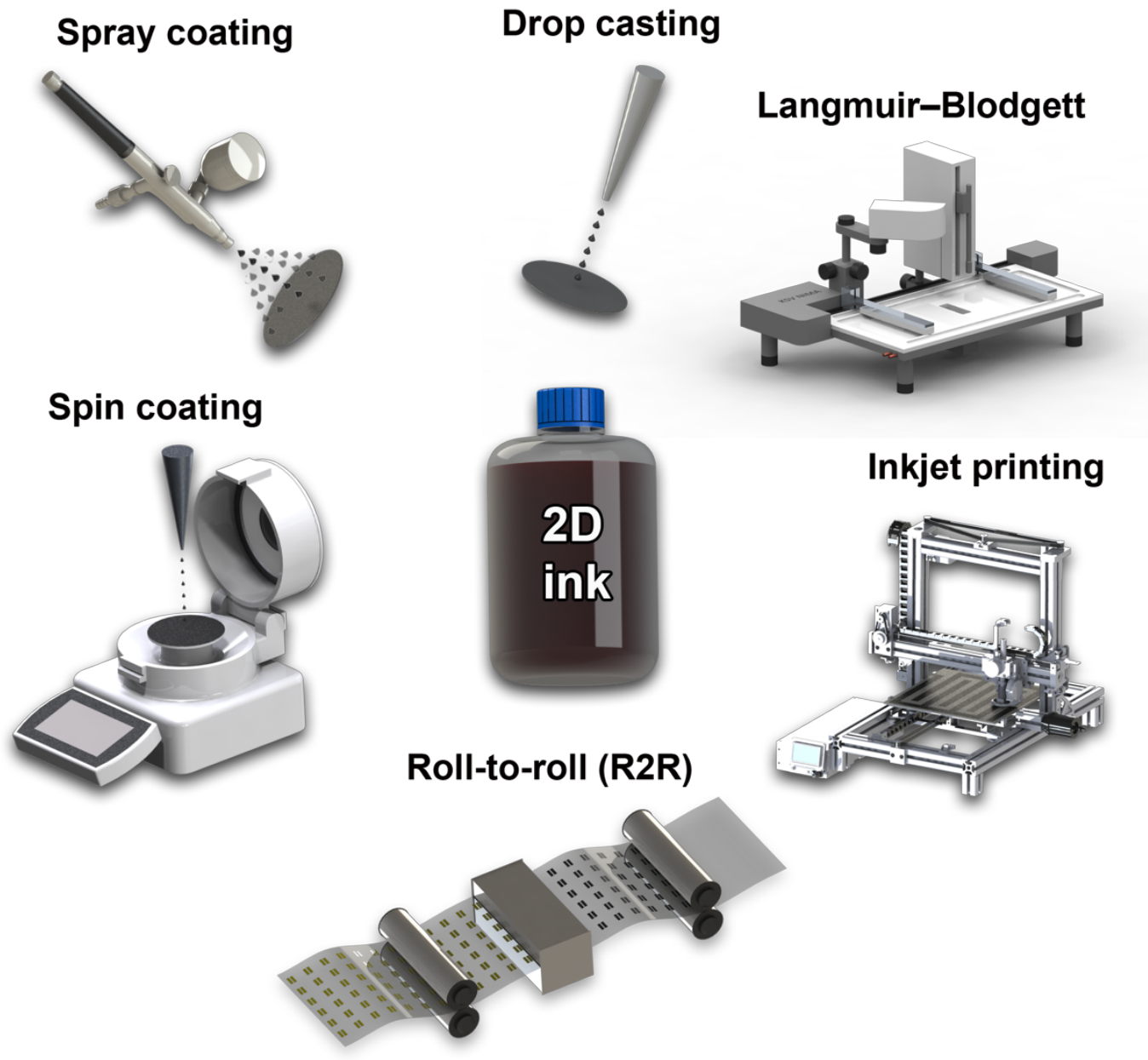

Figure 6. Schematic representation of well-established deposition techniques used for 2D inks deposition including spray-coating, spin-coating, drop-casting, dry-transfer, inkjet printing, Langmuir Blodgett (LB), and roll-to-roll (R2R) processing. 


\section{WILEY-VCH}

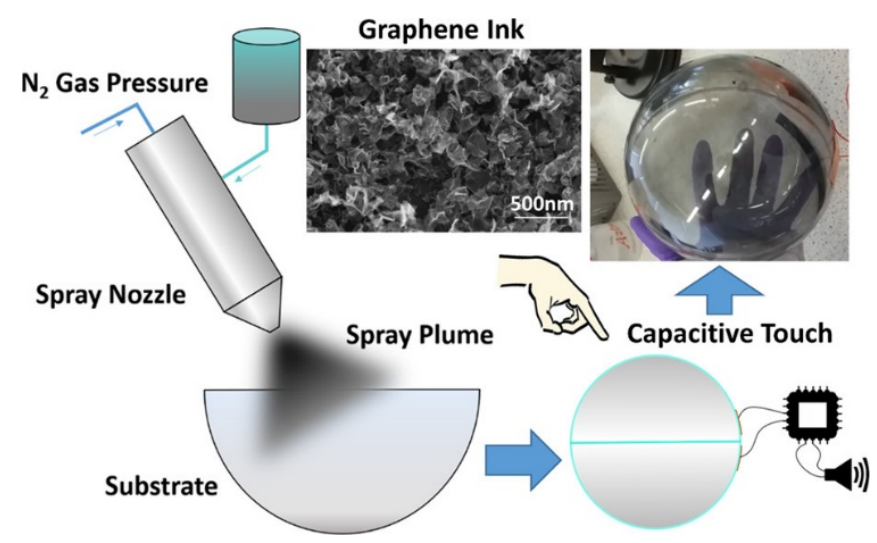

Figure 7. Schematic of the spray coating process with an air-assist spray nozzle being used to spray graphene ink around a 3D PMMA hemisphere. Photo of the spray-coated semitransparent capacitive-touch device. Reproduced with permission. ${ }^{[155]}$ from the American Chemical Society.

Table 1. Parameters describing concentration of graphene solution, quality of the graphene flakes and conductivity of graphene samples by using the most common LPE methods.

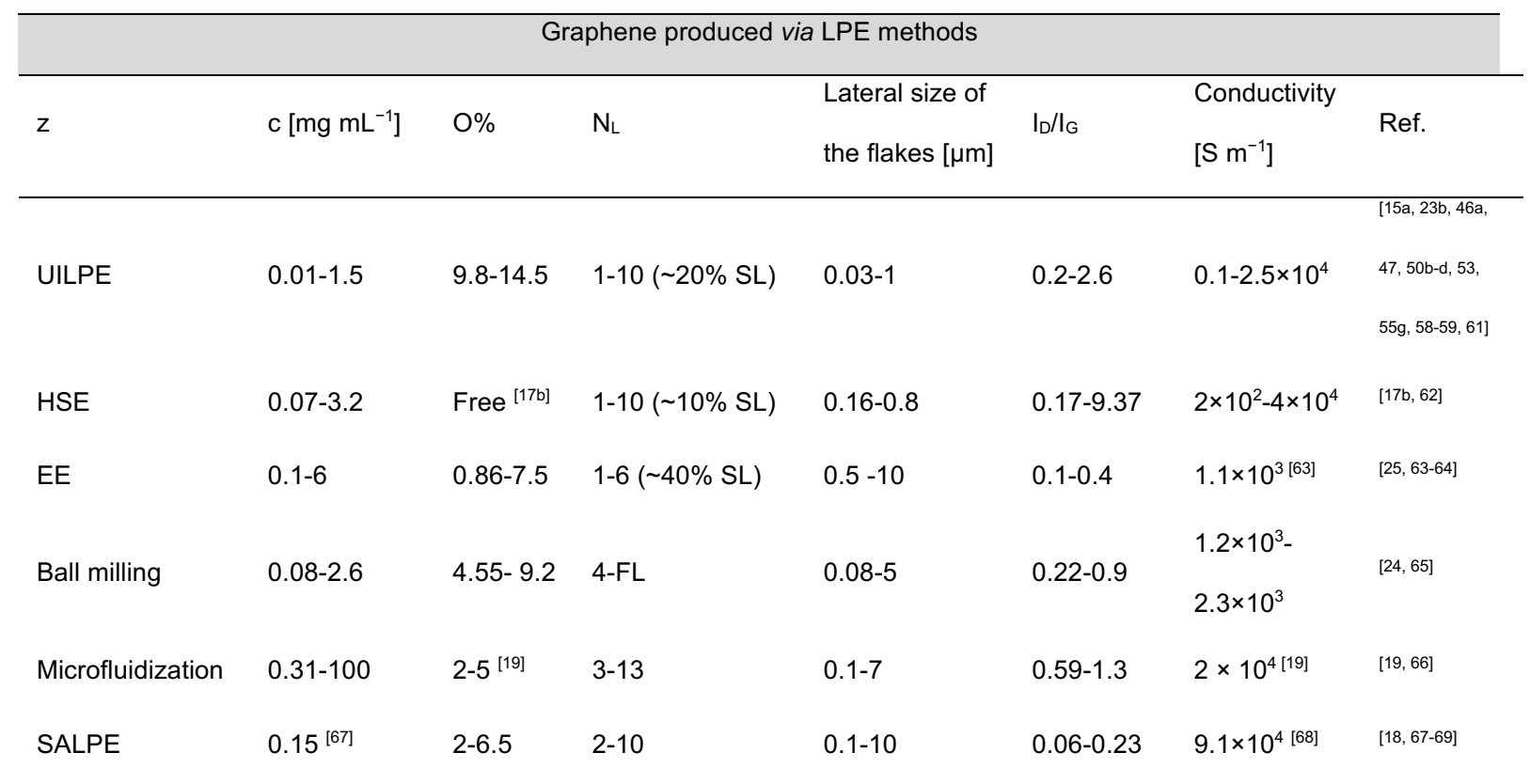

c- concentration of graphene dispersion $\left(\mathrm{mg} \mathrm{mL}^{-1}\right)$ determined by spectroscopic analysis; $\mathrm{O} \%$-percentage of oxygen by XPS analysis; $\mathrm{N}_{\mathrm{L}^{-}}$number of graphene layers estimated by TEM and AFM; $\mathrm{I}_{\mathrm{D}} / \mathrm{I}_{\mathrm{G}^{-}}$the ratio of the $\mathrm{D}\left(1350 \mathrm{~cm}^{-1}\right)$ and $\mathrm{G}\left(1600 \mathrm{~cm}^{-1}\right)$ bands areas on the Raman spectrum. 
Table 2. Parameters describing the quality and electronic properties of TMDs flakes obtained by different LPE methods.

\begin{tabular}{|c|c|c|c|c|c|}
\hline \multicolumn{6}{|c|}{$\mathrm{MoS}_{2}$ produced via LPE } \\
\hline & \multirow[b]{2}{*}{$1 \mathrm{~T} / 2 \mathrm{H}$} & \multirow[b]{2}{*}{$\mathrm{N}_{\mathrm{L}}$} & \multirow[b]{2}{*}{$\mathrm{I}_{\mathrm{on}} / \mathrm{I}_{\mathrm{off}}$} & \multicolumn{2}{|c|}{ Hole mobility $\left[\mathrm{cm}^{2} \mathrm{~V}^{-}\right.$} \\
\hline & & & & $\left.1 \mathrm{~s}^{-1}\right]$ & Ref. \\
\hline UILPE & $2 \mathrm{H}$ & $1-20(\sim 20 \% \mathrm{SL})$ & $2-100$ & $0.01-195$ & {$[70-74,82]$} \\
\hline HSE & $2 \mathrm{H}$ & $2-12$ & - & - & {$[17 a]$} \\
\hline EE & $2 \mathrm{H}$ & $1-5$ ( 10\% SL) & $10^{3}-10^{6}$ & $1.2-2$ & {$[16 \mathrm{~b}, 83]$} \\
\hline \multicolumn{6}{|c|}{$\mathrm{WS}_{2}$ produced via LPE } \\
\hline UILPE & - & $1-20(\sim 15 \% \mathrm{SL})$ & 600 & 0.22 & {$[70-71]$} \\
\hline \multicolumn{6}{|c|}{$\mathrm{MoSe}_{2}$ produced via LPE } \\
\hline UILPE & - & $2-20$ & 100 & 0.18 & [71] \\
\hline \multicolumn{6}{|c|}{$\mathrm{WSe}_{2}$ produced via LPE } \\
\hline UILPE & - & $2-30$ & 100 & 0.08 & [71] \\
\hline
\end{tabular}

1T-metallic and 2H-semiconducting phases of $\mathrm{MoS}_{2} ; \mathrm{N}_{\mathrm{L}}$-number of TMDs layers determined by TEM and AFM; Ion/Ioff-the ratio of currents in the on-and off-state.

Table 3. Parameters describing the quality and electronic properties of BP nanosheets obtained by different LPE methods.

\begin{tabular}{lccccc}
\hline & \multicolumn{5}{c}{ BP produced via LPE } \\
\hline & $\mathrm{O} \%$ & $\mathrm{NL}$ & lon/loff & Hole mobility $\left[\mathrm{cm}^{2}\right.$ & Ref. \\
UILPE & $5^{[84]}$ & $1-25(\sim 25 \% \mathrm{SL})$ & $1.6 \times 10^{3}-3 \times 10^{5}$ & $0.58-25.9$ & {$[28,31,43,77-78,84]$} \\
EE & - & $5-15$ & $60-252$ & $10^{4}-1.2 \times 10^{5}$ & {$[85]$}
\end{tabular}

O\%-percentage of oxygen by XPS analysis; $\mathrm{N}_{\mathrm{L}}$-number of BP layers determined by TEM and AFM; Ion $/ \mathrm{I}_{\text {off- }}$ - the ratio of currents in the on-and off-state. 